\title{
Mechanisms and Use of Neural Transplants for Brain Repair
}

\author{
Stephen B Dunnett ${ }^{1^{*}}$, Anders Björklund ${ }^{2}$ \\ ${ }^{1}$ School of Biosciences, Cardiff University, Museum Avenue, Cardiff CF10 3AX, UK. \\ ${ }^{2}$ Wallenberg Neuroscience Center, Lund University, BMC A11, 22184,Lund, Sweden. \\ * Corresponding author. Tel: +44 2920 875188, Fax: +44 2920 876749, \\ email address:dunnett@cf.ac.uk.
}

\begin{abstract}
Under appropriate conditions, neural tissues transplanted into the adult mammalian brain can survive, integrate and function so as to influence the behaviour of the host, opening the prospect of repairing neuronal damage and alleviating symptoms associated with neuronal injury or neurodegenerative disease. Alternative mechanisms of action have been postulated : non-specific effects of surgery; neurotrophic and neuroprotective influences on disease progression and host plasticity; diffuse or locally-regulated pharmacological delivery of deficient neurochemcials, neurotransmitters or neurohormones; restitution of the neuronal and glial environment necessary for proper host neuronal support and processing; promoting local and long distance host and graft axon growth; formation of reciprocal connections and reconstruction of local circuits within the host brain; up to full integration and reconstruction of fully functional host neuronal networks. Analysis of neural transplants in a broad range of anatomical systems and disease models, on simple and complex classes of behavioural function and information processing, have indicated that all of these alternative mechanisms are likely to contribute in different circumstances. Thus, there is not a simple or typical mode of graft function; rather grafts can and do function in multiple ways, specific to each particular context. Consequently, to develop an effective cell-based therapy, multiple dimensions must be considered: the target disease pathogenesis; the neurodegenerative basis of each type of physiological dysfunction or behavioural symptom; the nature of the repair required to alleviate or remediate the functional impairments of particular clinical relevance; and identification of a suitable cell source or delivery system, along with the site and method of implantation, that can achieve the sought for repair and recovery.
\end{abstract}

\section{Keywords}

neural transplantation, mechanisms, brain repair, functional recovery, neuroplasticity, trophic mechanisms, reinnervation, circuit repair, nigral grafts, striatal grafts, hippocampal grafts, spinal cord grafts, bridge grafts. 


\section{INTRODUCTION}

The transplantation of neural cells and tissues into the mammalian central nervous system has been a topic of scientific investigation since the late nineteenth century, and evidence for successful engraftment using a variety of immature tissue sources, implanted into a variety of central and peripheral targets, was achieved from multiple labs during the first half of the twentieth century (Björklund \& Stenevi, 1985a, Dunnett, 2010). However, it was only in the 1970s that the first reliable methods for neural transplantation into the adult (Stenevi et al., 1976) or neonatal (Das \& Altman, 1971, Lund \& Hauschka, 1976) brain were introduced.

Once these techniques were established, many investigators began using this new tool for the anatomical analysis of nervous system development, regeneration and plasticity (see Björklund and Stenevi, 1985; Sladek \& Gash, 1984; Wallace \& Das, 1983 for early overviews of this emerging field). In addition, there rapidly developed a parallel interest in the functional capacity of transplanted cells - specifically, whether disability resulting from neuronal loss or circuit damage in the adult CNS might be alleviated by cell transplantation aimed to replace the lost neurons and/or repair their connections. Within a five year period at the turn of the 1980s functional recovery from mechanical, toxic and genetic lesions of the central nervous system was seen in a multiplicity of model systems. These included alleviation of motor symptoms in parkinsonian rats by transplants of embryonic dopamine neurons (Björklund \& Stenevi, 1979, Perlow et al., 1979, Björklund et al., 1980); normalisation of polyuria and polydipsia in diabetic rats by transplants of vasopressin-secreting hypothalamic neurons (Gash et al., 1980); restitution of normal sexual function in hypogonadal mice by transplants of $\mathrm{GnRH}$-secreting hypothalamic neurons (Krieger et al., 1982); restitution of diurnal rhythms in SCN lesioned or genetic mutant mice (Drucker-Colín et al., 1984, Ralph et al., 1990); normalisation of hippocampus-dependent maze learning by cholinergic neurons in the denervated or aging hippocampus (Dunnett et al., 1982, Low et al., 1982, Gage et al., 1984); and alleviation of both motor and cognitive deficits associated with striatal lesion models of Huntington's disease (HD) by embryonic striatal grafts (Deckel et al., 1983, Isacson et al., 1984, 1986, Dunnett et al., 1988).

In all these models, transplant-derived recovery was seen to be associated with anatomical survival of neurons exhibiting an appropriate morphology and transmitter type to replace the lost cells, outgrowth of axons making synaptic connections with appropriate host targets, and neurochemical and electrophysiological restitution of relevant neurotransmitter signalling. With the enthusiasm of successes seen in such widely diverse systems, it was therefore entirely natural to conclude that any observed functional recovery could be attributed to replacement of lost neurons and repair of the damaged host neural circuitry. However, even from an early stage, it was noted that all successful models involved transplantation of neuronal populations involved in "diffuse" modes of communication - for example, the dopamine innervation of the striatum, or the cholinergic, noradrenergic and serotonergic innervation of hippocampus and cortex, all of which have been considered as components of the diffuse reticular forebrain activating systems. Following a similar reasoning, hypothalamic, adrenal and other neuroendocrine neurons are all involved in secretion of blood-borne neuro-hormonal signalling molecules. Consequently, a clear strand of scepticism soon emerged about whether similar recovery could ever be achieved by cell replacement in more precisely wired "point-to-point" systems such as those involved in cortico-thalamic, visual system, 
cerebellar or spinal cord communication (Sotelo \& Alvarado-Mallart, 1987, 1991, Worthington \& Harvey, 1990).

The purpose of this introductory chapter is to pursue this topic further and outline our growing understanding of the diverse range of influences that transplanted cells may exert over the host nervous system and the behavioural function of the host animal. We have sought to identify the different types of integration and reconstruction that may optimise functional repair, at the same time as we recognise opportunities for therapeutic efficacy that do not require full reconstruction of damaged circuitry. This then provides a conceptual framework for the chapters that follow, which develop alternative themes and strategies for functional cell-based repair in more detail.

\section{ALTERNATIVE MECHANISMS OF FUNCTIONAL RECOVERY}

Our recognition of the need to identify multiple mechanisms of graft function first emerged from comparison of the behavioural recovery that was seen when grafting embryonic ventral mesencephalic ("nigral") and ganglionic eminence ("striatal") tissues within the basal ganglia in rodent lesion models of Parkinson's disease (PD) and Huntington's disease (HD), respectively. Even though the two models involve disruption and repair within the same anatomical circuits of the basal ganglia, and assessed functionally using the same set of behavioural tests, the actual profiles of functional recovery turned out to be very different in the two models (Björklund et al., 1987).

Notably, both nigral grafts in the 6-OHDA-lesioned dopamine-depleted parkinsonian striatum and striatal grafts in the excitotoxically lesioned HD-like striatum are capable of alleviating simple motor deficits, such as hypo/hyperactivity after bilateral lesions and turning behaviour in animals with lesions restricted to one hemisphere. However, whereas the nigral grafts appear to have a simpler task in hand (to replace a single diffuse dopaminergic input to the denervated striatum, leaving all other aspects of striatal circuitry intact) than the striatal grafts (where the loss of intrinsic striatal neurons following excitotoxic lesion destroys interneurons, projection neurons and their circuit connections), yet the striatal grafts were able to alleviate a broader range of cognitive, complex motor, and motor learning functions, such as in skilled paw reaching (Dunnett et al., 1987, 1988, Montoya et al., 1990), that are relatively resistant to alleviation by the nigral grafts.

Insert Figure 1. about here

The most obvious difference between the two models (see Figure 1 ) is that to be fully effective nigral grafts require ectopic placement of the grafted dopamine neurons into the denervated striatal target. Transplants of fetal dopamine neurons into the lesioned substantia nigra (from where the host dopamine neurons were lost) survive and can be made to reconnect to the denervated forebrain targets in a remarkably precise manner (Wictorin et al. 1992; Thompson et al. 2009; Grealish et al. 2013), but the functional recovery obtained using this approach has so far been quite limited (Björklund et al., 1983). Conversely, to be effective, striatal grafts are replaced homotopically into the striatal area of host cell loss, from where they are seen to project long distance axons to the host pallidum and nigra (Wictorin et al., 1990b, Wictorin et al., 1991), as well as to attract 
regenerative sprouting of adult host cortical, thalamic and nigral afferents that have lost their intrinsic targets by the excitotoxic lesion (Wictorin, 1992).

Thus, different mechanisms of action for the two graft types are suggested, even when involving the same implantation site and functional behaviours. To be maximally effective, nigral grafts are implanted ectopically so as to restore dopaminergic neurotransmission in the reinnervated striatal targets (Figure 1C), which may act to provide local reactivation similar to that provided by L-dopa or dopaminergic agonists in patients. Such grafts may provide dopamine replacement at more physiological levels targeted explicitly at locally regulated synaptic sites than can be readily achieved by a synthetic local drug delivery system (Hargraves \& Freed, 1987), but the underlying mechanism is still essentially pharmacological. In their ectopic location, both anatomical tracing studies as well as electrophysiological recordings have provided evidence that the dopamine neurons grafted into the dopamine-denervated striatum receive afferent inputs from the host - striatum, frontal cortex and raphé nuclei, in particular (Doucet et al., 1989, Fisher et al., 1991, Sorensen et al., 2005). But the full complement of inputs available to the nigral dopamine neurons in their normal midbrain locations is clearly not restored in such ectopic grafts.

The excitotoxic striatal model is quite different in that there are no pharmacological agents akin to Ldopa in PD that can alleviate the overt motor or cognitive symptoms of intrinsic striatal lesion or HD. The striatum has a central role in the selection and initiation of cortically-derived plans for actions, and dysfunction following lesions, or in the human disease, is considered to be attributable to an essential disconnection of the cortico-striatal (in particular fronto-striatal) circuits that underpin goal-directed action (Rosvold, 1972). The observation that homotopic striatal grafts provide effective alleviation of motor, motor learning and cognitive deficits in excitotoxic lesioned rats corroborates the hypothesis that homotopically-placed striatal grafts can restore afferent and efferent circuitry in the adult nervous system (Figure 1E), the substrates for which have been amply demonstrated at light microscopic (Wictorin, 1992), biochemical (Campbell et al., 1993, Sirinathsinghji et al., 1988, Sirinathsinghji et al., 1993), electrophysiological (Rutherford et al., 1987, Xu et al., 1991, Nakao et al., 1999) and ultrastructural (Clarke \& Dunnett, 1993) levels of circuit analysis. Moreover, it is notable that striatal grafts placed into the globus pallidus (comparable to the ectopic placement of nigral grafts) is without functional efficacy (Isacson et al., 1986). This theme of circuit reformation is elaborated more fully in Section 3, below.

The subsequent comparison of a wide range of model systems has led to the recognition that there is no such thing as THE mechanism of graft action. Rather, grafted neurons and other tissues could (and in practice do) influence host structure, neuronal processing and function in a variety of ways. In particular, the actual mode of action is clearly dependent upon multiple factors: which host cells are affected; the nature of the underlying disease process; whether neurodegeneration is progressive or remitting; and the particular behaviours/symptoms that are involved (each of which may have quite different neural substrates and demands), alongside which donor cells are implanted; where they are placed; and the extent and time course of their integration into the host brain. This has led to the formulation of several frameworks for analysis of the diverse mechanisms of graft action by both ourselves and others (Björklund et al., 1987, Dunnett \& Björklund, 1987, 1994b, Freed et al., 1985, 1990, Gash, 1987, Buzsaki \& Gage, 1988, Gage \& Buzsaki, 1989). An updated version of the summary table from our own 1994 review (Dunnett \& Björklund, 1994b) is presented in Table 1. 
Insert Table 1 about here

\section{Non-specific mechanisms}

The manifold and diverse effects of surgical interventions have become better understood in the intervening 20 years. Neurosurgical approaches to symptom alleviation in PD, e.g., lesions (Hallett et al., 1999) or 'deep-brain stimulation' (DBS) (Perlmutter \& Mink, 2006) in thalamic and basal ganglia circuits, have been particularly informative in this regard. Indeed, DBS has significantly raised the bar for developing new stem-cell therapies for PD which must be safer, more reliable, more costeffective, and/or more broadly efficacious than the current surgical alternatives. Ultimately, however, surgical lesion or stimulation therapies are symptomatic and do not alter the course of the underlying disease. Rather, they are providing a much clearer analysis of the ways in which complementary circuit blockade, whether by irreversible lesion or reversible depolarisation block, can restore a tonic rebalancing of striatal output pathways compensating against the primary cell loss. Consequently, a truly reparative cell replacement therapy still has considerable appeal provided it can be delivered reliably, safely and cost-effectively.

A related way in which non-specific effects of surgery may affect functional outcome relates to the potential for transplant growth (and in particular overgrowth) to generate 'space occupying lesions'. In 1994 the resulting influence on host function was considered invariably adverse, and indeed the potential of residual proliferative cells for metastatic overgrowth continues to be one of the major safety concerns for stem-cell derived grafts whatever the CNS target. Nevertheless, the physical space occupying effects of graft growth can in some circumstances be beneficial, as exhibited by the use of spinal cord tissues to fill and inhibit further enlargement of syrinx formation in traumatic spinal cord injury (Falci et al., 1997).

\section{'Trophic' mechanisms}

A second major area of development has been the growing insights into the specificity and targeting of trophic mechanisms of recovery. It is almost 120 years since Forssman (Forssman, 1898) coined the term 'neurotopism' to signify chemical signalling over a distance to attract nerve regeneration towards a remote target. These studies were followed by Tello's (1911) demonstration of successful grafting of peripheral nervous tissue into the cerebral cortex with the capacity to stimulate and attract regeneration of central nerve fibres, an effect that became well established over the following years (Björklund \& Stenevi, 1985a). The use of growth-attracting conduits remains a central principle of promoting axon regeneration in the injured spinal cord and elsewhere (see Section 6 on bridge grafts, below). The importance for cell transplantation was the recognition that transplants could potentially be used not only for cell replacement per se, but as an effective vector to deliver trophic molecules that are typically too large to cross the blood brain barrier, to precise targets in the depths of the nervous system, in order to promote the survival, differentiation and growth of endogenous neurones, to protect against traumatic injury or neurodegenerative disease, to enhance and modify the function of surviving neurons, and to stimulate and direct axonal regeneration and neuronal plasticity via both regenerative and collateral sprouting.

Initially, neurotrophic mechanisms were postulated as a hypothetical process to account for situations where the grafted cells were seen to stimulate sprouting and growth of host fibre 
pathways. In a number of studies, grafts were shown to promote sustained functional recovery even in the absence of graft survival. For example, transplants of adrenal medulla cells - considered for a period as an alternative to replace lost dopamine neurons in Parkinson's disease - were observed to yield modest recovery in tests of drug-induced rotation in toxin lesioned animal models, even in the absence of survival of the catecholamine-secreting chromaffin cells within the grafts. The most compelling interpretation of this conundrum was offered by Martha Bohn and colleagues with the demonstration that recovered grafted animals exhibited significant increase in striatal THimmunoreactive terminals, interpreted as sprouting of spared dopamine fibres into the more denervated areas of the dorsal striatum, consistent with stimulation of endogenous compensatory plasticity induced by release of trophic factors from the grafted cells (Bohn et al., 1987).

With the elaboration over the following decades of multiple new factors with different molecular targets and different modes of action, along with developments of gene editing strategies to modify grafted cells, a more rational approach to using transplants to promote neuroprotection and neuroplasticity has become increasingly popular. In particular, many labs have developed cell lines engineered to secrete, often under inducible control, many key trophic molecules, including NGF (Ernfors et al., 1989, Strömberg et al., 1990, Cunningham et al., 1991, Dekker et al., 1994, MartinezSerrano et al., 1995a, Martinez-Serrano et al., 1995b, Marei et al., 2015), BDNF (Frim et al., 1994, Yoshimoto et al., 1995, Alberch et al., 2002), NT3 (Senut et al., 1995, Wang et al., 2014), GDNF (Nakao et al., 2000, Espejo et al., 2001, Alberch et al., 2002, Chaturvedi et al., 2003), VEGF (Garcia et al., 2014), FGF (Uteza et al., 1999) and other neuroprotective agents such as antioxidants (Barkats et al., 1997) and molecules regulating the cell death pathways.

Moreover, the trophic influence is not only operating from graft to host. The growth, connectivity and integration of grafted neurons are themselves modulated by a complex of developmental, trophic and tropic influences. So, we can consider combining co-grafts, one to replace lost population of neurons, with a second to promote neuronal survival, differentiation, fibre growth and targeted connectivity with the host brain (Olson et al., 1990, Liang et al., 2013, Collier \& Springer, 1994, Cunningham et al., 1991, Niijima et al., 1995, Takayama et al., 1995, Deng et al., 2013). It may be possible to use such transplants to modulate graft and host neurons via a multiplicity of influences. We need to go beyond the original simple distinction between (survival-promoting) 'neurotrophism' and (remote targeting) 'neurotropism' (Lu et al., 2001) to distinguish between factors which regulate cell survival, differentiation, gene expression and functional activity at the level of the cell body, and other factors which modulate sprouting, directional outgrowth and guidance at the level of the growth cone of developing and regenerating axons. Such mechanisms will contribute importantly to the individual cell's interactions with its neighbours and its integration into the host neuronal network.

Rather than being considered as a non-specific mechanism, which tended to undervalue the specific neuronal replacement strategies of early cell therapy approaches, delivery of neurotrophic factors into deep brain targets, at physiological doses, on a sustainable basis, and potentially regulatable by molecular switches, is now viewed as an important component of the cell therapy tool box. Indeed, many current stem cell-based therapies are focused explicitly on delivering cellular and molecular factors that can enhance the survival and health of host brain neurons compromised by aging, disease or injury, and/or promote regenerative plasticity for reorganisation in the adult brain. 


\section{'Bystander' effects}

A particular form of the neuroprotective mechanism of functional activity has recently become popular, viz. the attribution of graft efficacy to a 'bystander effect'. This term is applied to situations where a graft is seen to exert a functional benefit even in the absence of survival of the grafted cells, as for the adrenal medulla studies from an earlier generation, described above. It has become particularly popular in the context of mesenchymal stem cell (MSC) grafts and related multipotent cell types, often with peripheral administration and putative homing to a dysfunctional target. Significant recovery, typically with rapid onset, has been reported in animal models of neuroinflammation (Martino \& Pluchino, 2006, Einstein et al., 2007), stroke (Bacigaluppi et al., 2009), demyelination (Uccelli \& Mancardi, 2010), brain trauma (Tajiri et al., 2013) and spinal cord injury but where long-term survival of the migrating cells cannot be detected. Such observations in the CNS are mirrored by the hypothesised mechanisms of MSC cell therapy in other organ systems also, such as cardiac repair (Lai et al., 2011).

To address these effects, a major focus of recent experimental research has been on the potential of neural stem/precursor cells to protect the CNS from inflammatory damage. In a major influential review, Martino and Pluchino (Martino \& Pluchino, 2006) have postulated a basis for the bystander effect in the response of neural stem/precursor cells to respond to inflammatory regulators and modulate the host inflammatory response. Thus, undifferentiated neural stem cells are responsive to a similar wide range of stem cell regulators, inflammatory mediators and growth factors as are the cells implicated in inflammatory conditions including experimental allergic encephalomyelitis (EAE) and human autoimmune disease, such as multiple sclerosis (MS). The immature grafted precursor cells are considered to exert a neuroprotective influence on slowly evolving neurodegenerative processes by dissipating host inflammatory reactions, reducing glial scar formation and inhibiting apoptotic cell death pathways (Bacigaluppi et al., 2009).

The optimism surrounding the 'bystander' phenomenon with the promise of an effective therapy even when the grafted cells do not survive, and the mechanism of action remains unspecified, is in danger of encouraging a premature rush to clinical application (Mack, 2011, Doeppner \& Hermann, 2014). However, in a recent review Martino (2016) concludes that "until the basic mechanisms that regulate stem cell function are determined, all triumph is misplaced". In the context of a more widespread concern about current trends to unregulated stem cell tourism (Kiatpongsan \& Sipp, 2009), the emphasis of all credible research programs should be not only on well conducted clinical research maintaining international trial standards, but also on the detailed basic research to unravel the mechanisms of any effects.

\section{Circuit integration}

Several chapters in the present volume seek to develop functional neural transplantation strategies to achieve a variety of disease-specific targets by such relatively diffuse mechanisms of trophic, neuroprotective or pharmacological delivery. However, there remain situations where functional recovery will require replacement of lost neurons, restoration of damaged connections, and reconstruction of complex neuronal circuitry of the host brain, i.e., true 'brain repair'.

But to what extent has true brain repair yet been achieved, and if so under what conditions and circumstances? The thrust of our earlier reviews (Björklund et al., 1994, 1987, Dunnett, 1995) was that the replacement and reconstruction of damaged circuits is indeed necessary for functional recovery of cognitive as well as motor function with striatal grafts in the lesioned striatum, and as 
discussed in further detail in Section 3, below, significant further evidence in support of that view has been subsequently acquired (Brasted et al., 1999b, Mazzocchi-Jones et al., 2009).

Another example in support of this possibility comes from studies of grafted interneurons. Wichterle et al. (1999) were the first to show that interneuron precursors derived from the median ganglionic eminence (MGE) have a remarkable propensity to migrate and integrate in the brain and spinal cord. This has opened up a new line of work using interneuron transplants as a way to modify the excitability and function of neural networks, especially in animal models of epilepsy (for review, see (Southwell et al., 2014).

During normal development MGE-derived precursors migrate over long distances to populate wide areas of the forebrain, including neocortex, hippocampus and striatum. After transplantation MGEderived interneuron precursors are seen to disperse widely within the targeted area, neocortex (Wichterle et al., 1999, Alvarez-Dolado et al., 2006, Tanaka et al., 2011), hippocampus (Hunt et al., 2013, Henderson et al., 2014), striatum (Wichterle et al., 1999, Martinez-Cerdeno et al., 2010), amygdala (Hunt et al., 2013) and spinal cord (Braz et al., 2012). The grafted interneuron precursors migrate up to $5 \mathrm{~mm}$ in neonates (Alvarez-Dolado et al. 2006) and $1.5-2.5 \mathrm{~mm}$ in the adult mouse brain and spinal cord (Hunt et al., 2013, Braz et al., 2012), differentiate into fully mature GABA-ergic neurons, and become both functionally and structurally connected with the neuronal elements of the host. They are highly efficient in normalizing neuronal hyperexcitability, e.g., in animal models of epilepsy (Baraban et al., 2009, Hunt et al., 2013, Henderson et al., 2014) and neuropathic pain (Braz et al., 2012), thus providing some of the best examples of functional integration of new neurons into host circuitry.

For further discussion of this interesting approach, see Chapter 16, this volume, by Spatazza and Alvarez-Buylla, and Chapter 17, by Braz, Basbaum and colleagues. In the rest of this chapter we focus on transplant-induced restoration of neural circuitry in the CNS regions where the most interesting research has been performed along these lines: basal ganglia, cortex, hippocampus and spinal cord.

\section{TRANSPLANT-INDUCED FUNCTIONAL RECOVERY IN STRIATAL SYSTEMS}

\section{Integration of grafted neurons into basal ganglia circuitry}

As indicated above, transplants of striatal precursor neurons derived from dissection of the embryonic ganglionic eminence into the striatal lesion model of HD provides perhaps the clearest demonstration of the requirements for circuit repair underlying functional recovery currently available - as illustrated in Figure 1C and reviewed previously (Dunnett, 1995, 2006, Dunnett et al., 2000).

The first support for this hypothesis was provided by the demonstration of functional recovery in a series of experiments involving bilateral transplantation of whole ganglionic eminence (WGE)derived tissue cell suspensions into neostriatum of rats that had previously received bilateral striatal lesions made with the axon sparing excitotoxin ibotenic acid. These grafts were seen to provide extensive neuronal replacement of new striatal like structures in the lesioned area, that stained for a variety of neurochemical and receptor markers of normal striatum, and contained large numbers of neurons exhibiting both the predominant morphology of DARPP-32 positive medium spiny GABAergic projection neurons (Graybiel et al., 1989, Wictorin et al., 1989b) and smaller numbers of 
neurons with the morphological features of all six major striatal cell types (Helm et al., 1990, Clarke et al., 1994).

More detailed analysis indicated a distinct patchy organisation of the graft tissue, reflecting the reaggregation with the grafts into distinct compartments comprising striatal like tissues of all neuronal types (the patch or ' $\mathrm{P}$-zones') interspersed by non-striatal cell populations (the NP zones) that are negative for striatal markers but comprise neurons with cortical- and pallidal-like phenotypes (Graybiel et al., 1989, Wictorin et al., 1989b). Since the WGE from which the grafts are dissected comprise precursors of all ventral forebrain areas including cortical, pallidal and striatal neurons, the admixture is not surprising. More notable is that the fact that the cells grafted as a dissociated cell suspension self-organise into separate striatal and non-striatal like compartments, and that the normal striatal host afferents from cortex, thalamus, nigra and raphé that are spared by the excitotoxic lesions, grow and reconnect preferentially with grafted neurons within the striatal compartment (Wictorin et al., 1989b, Liu et al., 1990, Labandeira-García et al., 1991, LabandeiraGarcía \& Guerra, 1994).

Such grafts are functional in that they appear to have the capacity to alleviate deficits of the host animals not just in simple motor tests such as lesion-induced hyperactivity or rotation in bilateral and unilateral lesioned animals, respectively, but also in a variety of maze learning tasks such as $T$ maze position learning, delayed alternation, water maze and radial maze working memory (Isacson et al., 1986, Aihara et al., 1994, Deckel et al., 1986, Koide et al., 1993). Such tests involve the selection of appropriate choices in both spatial and temporal domains which are known to require implementation of motor outputs under prefrontal cortical 'executive control', and are dependent upon the integrity of cortico-striatal circuits for their proper execution (Rosvold \& Szwarcbart, 1964). Deficits in such tasks can be induced by either lesions or disconnection at any level in the thalamocortico-striato-pallidal circuit (Divac, 1972, Divac et al., 1967, 1978) and cannot be alleviated by pharmacological means or output stimulation/block. Thus, the hypothesis that the grafts were working by restoration of a damaged or disconnected circuit within the host brain was compelling. However direct exclusion of less specific alternative mechanisms of action is logically difficult and the acquisition of direct rather than corroborative evidence has proved challenging. Nevertheless, considerable such evidence has now been accumulated from diverse sources.

\section{Striatal circuit reconstruction}

First and foremost has been the now extensive anatomical evidence of circuit reconstruction. The first tracing studies using WGA-HRP crystals deposited with striatal grafts demonstrated retrograde tracing in adjacent spared areas of host striatum, the ipsilateral thalamus and substantia nigra and weak staining in the host neocortex, with the nigral afferents confirmed by fluorescence histochemistry as ramification of dopaminergic fibre terminals within patch zones within the grafts (Pritzel et al., 1986). A far more extensive series of afferent and efferent tracing studies was then undertaken in a series of interconnected studies performed by Klas Wictorin in the Lund laboratory. In the first study he used a combination of WGA-HRP and fluorescent tracers to map subcortical afferents from host substantia nigra, thalamus, raphé and amygdala, all of which constitute normal sources of striatal input (Wictorin et al., 1988). The second study used PhAL and Fluoro-Gold as anterograde and retrograde tracers to map innervation and rich terminal plexus ramification of cortical afferents into the grafts, with the same pattern of regional and laminar distribution in frontoparietal cortex to that seen in retrograde labelling of normal cortical striatal inputs (Wictorin 
\& Björklund, 1989). And in a third approach Wictorin and colleagues (Wictorin et al., 1989b, 1989c) used a combination of anterograde and retrograde tracers to demonstrate clear and reproducible efferent projections from grafted neurons to host globus pallidus, endopeduncular nucleus and substantia nigra pars reticulata, i.e., the principal targets of the normal striatal MSN projection neurons.

The extent of the capacity of WGE striatal grafts for rich fibre outgrowth to appropriate targets in the rat brain was further illustrated in two xenograft studies involving implantation of either mouse or human embryonic WGE tissues into the lesioned striatum of immunosuppressed rat hosts (Wictorin et al., 1990a). This approach allowed all graft derived fibres to be visualised using antibody staining against a mouse-specific neuronal marker, (M6, Wictorin et al., 1991; Labandeira-Garcia et al., 1991), or staining using a human specific neurofilament antibody (Wictorin et al., 1990b), and confirmed not only the richness of axon outgrowth from the grafts but the selectivity of the direction of outgrowth along normal fibre tracts to appropriate targets from the outset, refuting the equally plausible mechanism of random outgrowth in all directions followed by pruning of fibres that did not establish appropriate terminal connections.

It is important to note that grafts not only establish appropriate inputs and outputs with the host brain, but that the host afferents connect with host neurons at the ultrastructural level, making morphologically appropriate synaptic connections with the appropriate neuronal targets within the grafts (Clarke et al., 1988, Wictorin et al., 1989a). Clarke \& Dunnett (1993) combined anterograde degeneration from cortical lesions and retrograde tracing from globus pallidus with Golgi, GAD and TH staining at the ultrastructural level to demonstrate that degenerating host cortical axon terminals made morphologically appropriate symmetric synapses onto the heads of spines on MSN-like neurons within the grafts. Moreover, TH-positive host dopamine axons were seen to make asymmetric synaptic contacts onto the necks of spines of the same MSN-like neurons. These medium spiny neurons were shown to be GABAergic (by GAD-ir), and project to the host globus pallidus (by retrograde WGA-HRP labelling). In combination with a previous study, showing that the grafted striatal neurons can grow along the myelinated fibre bundles of the internal capsule to reinstate a normal synaptic input to the previously denervated neurons in the host globus pallidus (Wictorin et al., 1990b), these connectivity studies provide compelling evidence that the striatal projection neurons grafted into the excitotoxin-lesioned striatum become fully integrated into the (previously lesioned) host basal ganglia circuitry. Although not fully approaching the density of connectivity of the normal striatum, all the components necessary to restore a full cortico-striatalpallidal circuitry has been demonstrated. The extent to which this can be achieved in other parts of the central nervous system remains to be explored, but the fundamental possibility of true circuit reconstruction by implanted young neurons or neuroblasts does appear plausible.

\section{Functional striatal circuit repair}

The second level of analysis on functional relevance of such anatomical circuit repair was first addressed using electrophysiological and in vivo neurochemical monitoring. It was rapidly demonstrated by electrophysiological recordings grafted neurons exhibited appropriate patterns of low levels of spontaneous activity and responsiveness to dopaminergic modulation (Nishino et al., 1992, Walsh et al., 1988, Xu et al., 1991, Chen et al., 2002), although the detailed membrane properties did not always fully mimic those recorded from intact MSNs (Xu et al., 1991). Combined stimulation and recording in brain tissue slices has confirmed bidirectional transmission of action 
potentials and efficient synaptic communication to the post-synaptic neurons, from host cortex and thalamus onto graft MSNs and from the grafts onto host pallidal targets (Rutherford et al., 1987, Xu et al., 1991, Nakao et al., 1999).

The establishment of functional host-to-graft connectivity is further supported by studies using c-Fos expression as a cellular marker of stimulation-induced functional activity in the grafted neurons. Using this approach Mandel et al. (1992) showed that c-Fos is markedly activated in the grafted neurons in response to amphetamine, and that this activation occurred in clusters of cells located mainly within the DARPP-32-positive areas within the transplants, i.e., within the striatum-like graft compartment which is preferentially innervated by the host dopamine afferents. In a second study, Labandeira-Garcia and Guerra (1994) studied the induction of Fos protein in grafted striatal neurons following electrical stimulation of the host frontoparietal cortex. Double Fos and DARPP-32 immunohistochemistry revealed that the Fos-immunoreactive nuclei were concentrated in the DARPP-32-positive (i.e., striatum-like) patches, which contained approximately $60 \%$ of the density of Fos-positive nuclei in the normal striatum, indicating that host corticostriatal fibres not only form an axonal network within the graft but also induce postsynaptic responses which may contribute to the observed graft-induced amelioration of lesion-derived behavioural deficits.

In parallel, in vivo dynamic neurochemistry has been used to demonstrate restitution of GABA release both in the neostriatum itself (Campbell et al., 1993), and in pallidal and nigral targets (Sirinathsinghji et al., 1988, Aihara et al., 1994), suggesting functional inhibitory neurotransmitter signalling. Moreover, local regulatory feedback by grafted interneurons is suggested by the restitution of cholecystokinin-induced inhibition of striatal dopamine release, indicating grafted MSN feedback regulation of dopamine release from nigrostriatal afferents (Sirinathsinghji et al., 1993). So again, even if far from fully normal quantitatively, electrophysiological and neurochemical studies suggest the graft-derived reconstruction of a functional neuronal circuit capable of restoring neuronal signalling necessary to mediate functional information processing and communication within the host brain networks.

\section{Behavioural evidence for transplant-induced circuitry repair}

Further behavioural evidence of recovery linked to circuitry repair has been obtained in more complex and better controlled operant tasks involving various discriminative learning paradigms, which has allowed us to probe the locus of changes. Operant analyses have followed two basic paradigms. The first of these is the use of two retractable lever operant chambers (the 'Skinner' box) to train animals on a conventional delayed alternation rule with the additional feature of introducing variable delay intervals between trials (Dunnett et al., 1999). In addition to the conventional measure of the ability of the animal to learn and execute the delayed alternation rule on each successive trial, the variable delays allow an evaluation of the rate of forgetting between consecutive trials and thereby to monitor any disruption of short term ('working') memory. Initial studies in lesioned animals indicated that lesions in the medial prefrontal cortex, medial striatum or disconnection of the corticostriatal tract bilaterally all serve to disrupt performance on the operant delayed alternation task, and that the impairment is due to an 'executive' deficit in response sequencing required to implement the delayed alternation decision rule (with the striatal lesions inducing a characteristic perseverative tendency) rather than to an impairment in remembering the response sequence from trial to trial (Dunnett et al., 1999, 2005, White \& Dunnett, 2006). Striatal grafts alleviate the deficit, restoring the ability of the grafted animals to perform the task, albeit that 
they require a period of relearning to restore choice accuracy (Dunnett \& White, 2006) - an important clue to graft function that is elaborated further below.

The second operant paradigm to have been used extensively has been the choice reaction time task in the ' 9 hole box' operant chamber (Figure 2A), in which rats (or mice) are trained to hold their nose in the central hole and then detect and respond to light signals in one of the side holes (Carli et al., 1985). This task was first introduced by Carli and Robbins to assess the effects of unilateral 6-OHDA nigrostriatal lesions and found that unilateral dopamine depletions disrupted animals ability to respond to the side contralateral to the lesion, but were fully able to respond accurately on the ipsilateral side, whichever was the side of the light stimulus under a series of counterbalanced training conditions. Thus the nature of the unilateral dopamine lesion deficit is essentially motor, i.e., due to disrupted initiation and execution of a lateralised response in the contralateral side of the body, rather than to a sensory deficit or sensorimotor neglect in contralateral space (Carli et al., 1985).

We and others have subsequently shown that unilateral striatal lesions are equally associated with deficits in response output, rather than contralateral sensory neglect (Brown \& Robbins, 1989, Brasted et al., 1997). The implantation of striatal grafts had significant capacity to alleviate the ability of the rats to respond in contralateral space (Mayer et al., 1992, Döbrössy \& Dunnett, 1998, Brasted et al., 1999a, 1999b, 1999c, 2000). However, what was most noteworthy in these results was not the demonstration of recovery per se, but the observation that when the grafted rats were first placed back in the test boxes, even 6 months after transplantation, task performance was as impaired as that shown by lesion rats or naïve rats; however, the grafted rats then relearn the task rule and improve accuracy of choice performance over a similar 6-8 week time frame as exhibited by a naïve rat learning the task for the first time, whereas lesion rats are unable to relearn even with very extensive further training (Figure 2B). Thus, it appears that previously trained knowledge of the task contingencies is abolished by the lesions (it was fully retained by the control rats even with a 6 month delay in testing) but can then be relearned de novo in the presence of the graft.

In the light of a principal function of the striatum being the neural substrate for motor habit and stimulus-response learning (White, 1989, Gaffan, 1996, Packard \& Knowlton, 2002), these results strongly suggest that the grafted striatal neurons have become sufficiently integrated into the host neural network to provide an adequate substrate for (re-)learning motor skills and habits. Although these observations do not by themselves provide a direct demonstration that the reconstructed striatal circuitry is the actual substrate, a transfer-of-training design indicated that the retraining must be explicitly on the side involving the transplant circuits, and no amount of training on the contralateral side can contribute to the transplant-derived recovery (Brasted et al., 1999b).

Insert Figure 2. about here

\section{Striatal circuit plasticity}

Ultimately, behavioural and lesion studies can never provide direct evidence of the neural substrate of new learning. However, a particularly informative series of studies have tackled this issue at the cellular level using the Calabresi slice model of corticostriatal plasticity. In a long series of studies, Calabresi and colleagues have demonstrated long-term synaptic plasticity at the glutamatergic 
cortico-striatal synapse located on MSN dendritic spines. Directly akin to the standard hippocampal LTP model of hippocampal episodic memory introduced by Bliss and Lomo (Bliss \& Lømo, 1973, Bliss \& Collingridge, 1993), having established the stable level of EPSPs in MSNs in response to repeated single pulse cortical stimulation, a tetanic burst of cortical stimulation results in long-term change of the EPSPs responses in the postsynaptic neuron, which is in the form of depression (LTD) in the standard physiological corticostriatal model but is changed into an LTP in a non-physiological lowmagnesium medium (Calabresi et al., 1992).

Calabresi and his team have provided a detailed molecular analysis of the changes in synaptic signalling and pharmacological modulation of corticostriatal plasticity (Gubellini et al., 2004, Calabresi et al., 2007). We have used this model system (Figure 2C) to show that LTD is restored at the host corticostriatal synapse on grafted MSNs, which exhibits identical physiological magnitude and duration as the intact corticostriatal synapse (Figure 2D), the same features under both extracellular and intracellular recording conditions, a similar transition to LTP under conditions of low $\mathrm{Mg}^{2+}$ (Figure 2E), and the same responsiveness to dopaminergic modulation as seen in the intact circuit (Mazzocchi-Jones et al., 2009, 2011). These data provide the first, and perhaps so far only, direct evidence that the structural circuits reformed by a striatal grafts exhibit the physiological plasticity at the cellular level necessary to provide the substrate for relearning that is consistently observed at the behavioural level. Nevertheless, this topic is not static, and it is likely that new techniques in optogenetics, rabies virus tracing and DREADDs although not yet applied specifically to striatal grafts now provide the tools to yield dramatic new advances in our knowledge on striatal circuit communication at molecular and cellular levels than has hitherto been possible with our present relatively crude classic recording methods.

\section{TRANSPLANT-INDUCED RECOVERY IN HIPPOCAMPUS AND CORTEX DEPRIVED OF THEIR SUBCORTICAL INPUTS}

The ability of intra-striatal dopamine neuron grafts to restore dopamine neurotransmission and reverse dopamine-dependent behavioural deficits points to the possibility of using transplants of other types of neuromodulatory neurons, such as cholinergic, noradrenergic and serotonergic neurons, as a way to restore defective neurotransmission and promote functional recovery in dysfunctional forebrain targets, hippocampus in particular. The transmitter-specific histochemical methods used in these early brain transplant studies - the Falck-Hillarp histofluorescence method and the acetylcholine esterase (AChE) method - performed in the 1970s and 1980s, allowed visualization of grafted monoaminergic and cholinergic neurons in their entirety, including the totality of their projections in the host brain. In combination with classic anterograde and retrograde tracers and behavioural tests, these methods provided powerful tools to study the survival, growth and function of these types of neurons after transplantation to the brain and spinal cord.

\section{Transplantation of septal cholinergic neurons to the deafferented hippocampus}

The hippocampus proved to be a highly useful model to study the capacity of growth and function of transplanted neuroblasts. Hippocampus receives a range of regulatory sub-cortical inputs from cholinergic, noradrenergic and serotonergic systems, all of which can be removed by transection of the fimbria-fornix pathway. In our studies we have used transplants of cholinergic neurons derived 
from the fetal basal forebrain, noradrenergic neurons from fetal locus coeruleus, and serotonergic neurons from the fetal brainstem raphé region, implanted into or adjacent to the hippocampus in rats with uni-or bilateral lesions of the fimbria-fornix (Figure 3A,B). The results demonstrated a remarkable capacity of grafted cholinergic and monoaminergic neurons to re-establish extensive innervation patterns in the dentate gyrus and the hippocampal subfields, which mimicked closely those of the normal, intrinsic afferents (Björklund \& Stenevi, 1977, Gibbs et al., 1986, Nilsson et al., 1988b, Leanza et al., 1996) (Figure 3C,E). The grafted cholinergic neurons were shown to restore hippocampal acetylcholine release to near-normal levels, as assessed by microdialysis (Nilsson et al., 1990b), to normalize muscarinic receptor binding (Joyce et al., 1989, Dawson et al., 1989), and to form functional synaptic contacts with host target neurons, closely similar to those present in the intact hippocampus (Clarke et al., 1986, Segal et al., 1985).

Insert Figure 3. about here

Interestingly, the innervation patterns generated by the transplanted neurons differed not only between neurons with different transmitter phenotypes, but also between different subtypes of cholinergic neurons such that each cholinergic neuron type (from septum, striatum, brainstem or spinal cord) was seen to produce distinctly different innervation patterns (Gibbs et al., 1986, Nilsson et al., 1988a). The ingrowth and ramification of axons was blocked by the presence of an intact cholinergic innervation, and stimulated by removal of the intrinsic afferents, suggesting that axonal outgrowth from the grafted neurons is very precisely regulated by the re-innervated target (Lewis \& Cotman, 1983, Björklund et al., 1979).

Fimbria-fornix lesions are associated with distinctive patterns of functional deficits in a variety of maze learning tasks. The severe behavioural deficits are clearly not due to the loss of cholinergic afferents alone. The fimbria-fornix lesion removes not only the septal cholinergic input, but a wide range of subcortical afferents, including not only the noradrenergic and serotonergic ones but also the GABAergic septal input, which is known to be an important regulator of hippocampal physiology. Nevertheless, a broad range of studies performed in both rodents and primates have shown that the deficits in hippocampus-dependent learning and memory seen in animals with bilateral lesions of the fimbria-fornix can be reversed by transplants of septal cholinergic neurons (Figure 3D), although the effect is only partial and also variable between different tests (for review, see (Dunnett, 1991, Björklund et al., 1990, Ridley \& Baker, 1994, Sinden et al., 1994). Cholinergic reinnervation of the previously denervated target seems to be a necessary requirement for recovery to occur (Dunnett et al., 1982). This is further supported by the observation that graft-induced recovery in this model is correlated with the recovery of high-affinity choline uptake and is blocked by the cholinergic antagonist atropine (Nilsson et al., 1987, Li et al., 1992, Tarricone et al., 1991).

The behavioural recovery seen in these studies is only partial, and may not always occur despite good graft-derived cholinergic reinnervation (see, e.g., (Dalrymple-Alford et al., 1988, Cassel et al., 1990)). This is not surprising given the broad range of subcortical afferents damaged by the fimbriafornix lesion. To address this issue, Leanza et al. (1998) performed a study in rats with a more selective lesion of the basal forebrain cholinergic neurons, induced by intraventricular injection of the 192 IgG-saporin immunotoxin. In these animals, the acquisition of spatial learning in the water maze task was completely normalised by cholinergic neuron grafts implanted in hippocampus and 
frontal cortex (but unaffected by non-cholinergic control grafts). Although the intraventricular 192 IgG-saporin lesion is not fully specific for forebrain cholinergic neurons (non-specific damage includes Purkinje cells in cerebellum and striatal cholinergic interneurons) it is highly efficient in removing the cholinergic innervation of both hippocampus and cortex and it spares several of the important afferents damaged by the fimbria-fornix lesion, such as the serotonergic and noradrenergic systems and the GABAergic septo-hippocampal pathway. The Leanza et al (1998) study suggests that the functional recovery induced by cholinergic neuron transplants is more prominent when other major subcortical inputs, such as the serotonergic and GABAergic afferents, are spared. Indeed, it is known that cholinergic and serotonergic neurons interact, such that impairments induced by cholinergic blockade are amplified by lesions (or blockade) of the serotonin afferents. Thus, in the water maze task, combined cholinergic and serotonergic lesions induce more prominent impairments than lesions of the cholinergic system alone (Nilsson et al., 1988c, RichterLevin \& Segal, 1989). This is further supported by the finding in the classic fimbria-fornix lesion model that combined cholinergic and serotonergic grafts are more effective than grafts of cholinergic neurons alone (Nilsson et al., 1990a, Richter-Levin \& Segal, 1989).

Taken together, these data provide substantial evidence that transplants of forebrain cholinergic neurons can reinstate functional synaptic transmission in the subcortically denervated hippocampal formation, and that the "reafferentation" provided by the grafted neurons is sufficient to restore some aspects of hippocampal function lost in animals with lesions of the septo-hippocampal pathway. These effects are consistent with the neuromodulatory nature of cholinergic neurotransmission, such that the grafted septal neurons may function in a tonic, autoregulatory manner, similar to what has been proposed for intrastriatal dopamine neuron grafts, discussed above. Studies of graft-derived acetylcholine release, monitored by microdialysis, have provided evidence that the grafted neurons are spontaneously active, and that the activity is effectively modulated by changes in axonal impulse flow (Nilsson et al., 1990a). In this study we could show that acetylcholine release from the graft-derived axonal projection can be boosted - as in the intact septo-hippocampal pathway - by gentle sensory stimulation (handling), as well as by electrical stimulation of the host lateral habenula, suggesting that intra-hippocampal septal grafts can become functionally integrated into host neuronal circuitry, despite their ectopic location.

\section{Transplantation of basal forebrain cholinergic neurons to the deafferented neocortex}

This "reafferentation" approach has been explored also in animals with excitotoxic lesions of the nucleus basalis magnocellularis (NBM). The cholinergic neurons residing in this nucleus provide a modulatory innervation of the entire neocortex, the basalo-cortical cholinergic pathway, similar in function to the septo-hippocampal pathway discussed above. Excitotoxic lesion of the NBM is an effective tool to denervate the neocortex of its cholinergic afferents but, like the fimbria-fornix lesion, these lesions are non-specific and involve also non-cholinergic projections neurons located in the NBM region, as well as in the adjacent ventral globus pallidus. Thus, the behavioural deficits seen in animals with bilateral NBM lesions reflect only in part damage to the basalo-cortical cholinergic pathway (Dunnett, 1990, Semba, 2000). Indeed, the impairments observed in rats with more selective lesions of the basal forebrain neurons, obtained with the $192 \mathrm{lgG}$-saporin immuntoxin, are more subtle that those seen after excitotoxin (or fimbria-fornix) lesions (Torres et al., 1994, Perry et al., 2001, Chudasama et al., 2004). Nevertheless, grafts of cholinergic neurons from the fetal forebrain, implanted into the neocortex in rats with excitotoxic lesions of the NBM, have been shown to be effective in improving the performance in a number of learning tasks, 
including passive avoidance, T-maze alternation and radial maze learning (for review, see (Dunnett, 1990, Dunnett, 1991)). Most likely, the impairments influenced in these tests are associated with deficits in selective attention and discrimination of relevant task stimuli, rather than in learning and memory per se.

Overall, the results obtained in these studies support the idea that the grafted cholinergic neurons act in a fairly non-specific manner to improve the performance of the subcortically deafferented cortex linked to arousal and attention. Similar to the intra-hippocampal grafts, the intra-cortical transplants grow to establish a new, extensive AChE-positive innervation in the part of the frontoparietal cortex denervated by the NBM lesion. However, it is unclear whether any of the functional effects depend on re-establishment of synaptic connectivity. Indeed, studies performed in Rusty Gage's lab (Winkler et al., 1995, Dickinson-Anson et al., 1998), using intra-cortical or intrahippocampal grafts of fibroblasts engineered to secrete acetylcholine, have shown that significant improvement in performance in the water maze task can be obtained in the absence of any graftderived axonal terminal network suggesting that tonic, diffuse activation of cholinergic receptors is sufficient to improve cortical function in this model.

\section{ABILITY OF GRAFTED NEURONS TO REGENERATE LONG-DISTANCE AXONAL PATHWAYS}

The early studies using either transmitter specific histochemical methods or immunohistochemistry using species specific antibodies revealed an impressive capacity of grafted fetal neurons or neuroblasts to grow axons over long distances and in a remarkably precise, target-directed manner. This has been obtained not only in intact neonatal recipients, but also in adult mice and rats subjected to different types of denervating lesions. In adult recipients the outgrowing axons have been observed to extend not only within grey matter, but also along white matter tracts. As discussed above, such long-distance axon growth has been documented from striatal projection neurons grafted to the lesioned striatum (Wictorin et al., 1990b, Wictorin et al., 1991, Isacson \& Deacon, 1996, Armstrong et al., 2002) and from septal cholinergic neurons grafted to the lesioned septum (Leanza et al., 1996). Similar observations have been made in Jeff Macklis' lab in experiments using transplants of mouse cortical neuroblasts, pre-labelled with fluorescent beads and lipophilic dyes, and grafted into photolytic lesions of cortical projection neurons in adult mice (Hernit-Grant \& Macklis, 1996, Fricker-Gates et al., 2002). The most impressive results obtained in these early experiments, however, were observed in studies of noradrenergic, serotonergic or cortical neurons grafted to the lesioned spinal cord showing extension of axons over several centimetres (Nornes et al., 1983, Foster et al., 1985, Li \& Raisman, 1993).

\section{Studies using GFP expressing reporter mice}

The introduction of GFP-expressing reporter mice as a source of tissue for transplantation opened new possibilities to visualize and trace axonal projections from grafted neurons with a sensitivity and specificity that goes beyond what has been possible with the classic techniques. In our own work we have used this approach to trace axons from dopamine neuron transplants grafted to the intact or dopamine-depleted substantia nigra in adult mice (Thompson et al., 2009). In this case the graft-derived axons, expressing GFP under the tyrosine hydroxylase (TH) promoter, were seen to 
grow along the nigrostriatal pathway to innervate part of the caudate putamen, and along the median forebrain bundle (MFB) to innervate limbic forebrain regions, such as nucleus accumbens, olfactory tubercle and amygdala, accompanied by a significant improvement in the amphetamine rotation test. Gaillard et al. (Gaillard et al., 2009) have reported similar results using cells with GFP expressed under the less specific CBA promoter.

These studies have revealed a remarkable specificity of axonal outgrowth from the grafted DA neuroblasts. The extension of GFP-positive axons from the graft was clearly polarised: The vast majority of the axons exited the graft at the rostral pole, oriented rostrally along the intrinsic nigrostriatal fibre trajectory and the adjacent MFB, and the distribution of terminals in striatal, limbic and cortical areas matched closely the projection patters of the intrinsic midbrain dopamine neurons. The grafts contained the normal complement of A9 (nigral, Girk2-positive) and A10 (calbindinpositive) neuronal subtypes, and the retrograde tracing experiment indicates that graft neurons projecting to the striatum were of the correct, nigral phenotype. Along the nigro-striatal pathway the axons were arranged in a loose non-ramifying bundle, but as they reached the border between the globus pallidus and caudate-putamen they were seen to branch profusely, suggesting a direct influence of local cues on the ability of the growing axons to establish a new terminal innervation network in the denervated target. This was further supported by the observation that the growth and extension of the graft-derived GFP-positive fibres were much more restricted in non-lesioned hosts where the intrinsic dopamine projections were left intact.

A second example comes from studies performed in Afsaneh Gaillard's lab using transplants of GFPexpressing cortical tissue, obtained from E14 transgenic mice and grafted to a cavity made in the sensori-motor cortex of adult wild-type mice (Gaillard et al., 2004, 2007). Again, the results are striking: The graft-derived, GFP-expressing axons could be traced over large distances, within white matter tracts, not only to the contralateral cortex, but also to a number of sub-cortical targets, including striatum, thalamus, pontine nuclei and the cervical spinal cord. The pattern of projections was notably similar, albeit less abundant, to that observed in control mice following injection of an anterograde tracer (BDA) in the same cortical area, following the same axonal growth trajectories in the internal capsule, the cerebral peduncle and the pyramidal tract. Notably, about $30 \%$ of the graft-derived axons were seen to be myelinated, thus confirming that the ability for long-distance axon growth is not limited to neurons with non-myelinated axons. Electron microscopy showed GFP-expressing terminals making synaptic contacts with host cortical, striatal and thalamic neurons, and host neurons making both axo-somatic and axo-dendritic contacts with GFP-positive neurons in the transplant, suggesting that the grafted neurons had, at least in part, become integrated into host neural circuitry.

Tuszynski and collaborators have used cells from a transgenic rat expressing GFP under the ubiquitin promoter to trace connectivity from neural progenitors grafted to the lesioned spinal cord in adult rats (Lu et al., 2014, Kadoya et al., 2016)see also Chapter 14, this volume). The cells were embedded in a growth factor containing fibrin matrix and implanted into a lesion cavity transecting the cord at T3. At 7 weeks post-grafting GFP-expressing axons were seen to extend both rostrally and caudally over about $25 \mathrm{~mm}$ in each direction, some of them running within white matter and myelinated by host oligodendrocytes. Further analysis indicated the presence of both glutamatergic (vGlut-positive) and GABAergic (GAD65-positive) axons among the outgrowing fibres, and immunoelectron microscopy identified synaptic contacts between the graft-derived axon terminals and host neurons and dendrites. In the first study, over the 7-week period the grafts had filled the 
lesion cavity, and host axons originating in the brain stem (serotonin-expressing, or labelled with BDA injected into the brain stem reticular formation) were seen to extend into, but not beyond the graft (Lu et al., 2014), whereas in a subsequent study host axons were confirmed to extend up to $\mathrm{mm}$ into the distal segments of the spinal cord (Kadoya et al., 2016). Recovery of hindlimb movements was observed 4-6 weeks after grafting. Re-transection of the cord just rostral to the graft resulted in a complete loss of the recovered function when measured 1 week later. Electrical stimulation above the lesion were seen to generate evoked responses three segments below the graft site, but with prolonged latency, consistent with the hypothesis that the transplant had established functional connectivity across the lesion, via a synaptic relay through the graft.

\section{Studies using cells derived from embryonic stem cells}

The studies discussed above provide compelling evidence that the adult CNS retains the capacity to guide immature, growing axons over large distances and in a target-specific manner. Conversely, it seems clear that neuroblasts or young post-mitotic neurons that are programmed to establish longdistance connections with defined targets during normal development, are able to express this property also in the lesioned adult CNS. This regenerative capacity of grafted neuroblasts points to interesting therapeutic possibilities, and raises the question whether neurons derived from stem cells - embryonic stem cells (ESCs) and induced pluripotent stem cells (iPSCs), in particular - can be made to express the same capacity for pathway reconstruction. Studies performed during the last decade suggest that this may indeed be the case.

Early attempts to generate transplantable neurons from mouse or human ESCs were hampered either by poor overall survival or by inclusion of proliferative cells that generated expanding tumours at the graft site. Thanks to the more refined cell derivation protocols developed over the last few years these problems are now largely solved, and open up the prospect for interesting studies of ESC- and iPSC-derived cells implanted in diverse brain regions, such as cortex, striatum, substantia nigra and the damaged spinal cord. These new protocols build on knowledge derived from the study of normal brain development, taking advantage of insights into how morphogens, such as RA, SHH, BMP, fibroblast growth factors (FGFs) and WNTs, act to generate neuronal diversity in the CNS during embryonic development.

Particularly interesting results have been obtained in studies using ESC-derived cortical neurons. A number of recent studies have generated transplantable cortical progenitors from mouse (Gaspard et al. 2008, Idegushi et al. 2010, Michelsen et al. 2015) or human pluripotent stem cells (Denham et al., 2012, Espuny-Camacho et al., 2013, Steinbeck et al., 2012). In neonatal mice or rats, the ESCderived, GFP-labelled cells have been shown to survive well after transplantation to the neocortex. Some of them develop into mature pyramidal-like neurons with the capacity to extend axons along major corticofugal pathways, including the corpus callosum, the external and internal capsules and the cerebral peduncles. The GFP-positive graft derived innervations are consistent with pyramidal neurons of diverse layer identities: layer IV-type neurons innervating thalamus, layer V-type neurons innervating striatum and brainstem, and layer II-V-type neurons innervating ipsi-and contralateral cortex.

In the Espuny-Camacho et al. (2013) study, performed in neonatal immunodeficient NOD-SCID mice, the sub-layer specificity of the projection patterns was supported by retrograde tracing, showing that many of the human pyramidal-like neurons labelled from thalamus expressed the layer IVmarker TBR1, and that the neurons labelled from the superior colliculus expressed the layer V- 
marker CTIP2. Interestingly, Gaspard et al. (2008) have shown that the laminar commitment of the neurons depends on the duration of time in culture: the ones generated first (at 12 days of culture) project primarily to thalamus (consistent with deep-layer neurons) and those generated later (at 1417 days of culture) project more prominently to cortex (consistent with neurons in more superficial layers).

More recently, Michelsen et al. (2015) have extended this work to adult mice with excitotoxic lesions of visual or motor cortex. The results show that the regional specification of the grafted neurons is important for establishing specific patterns of connectivity. Extension of axons along the occipital cortical pathways, from grafts placed in the visual cortex, could be achieved when transplanting ESC-derived progenitors with molecular signatures of occipital cortex but not after transplantation of cells with signatures of motor cortex. These findings suggest that the ESC-derived cortical progenitors possess intrinsically specified programs for the establishment of target-directed connectivity. Interestingly, the grafted occipital cortical neurons, but not those derived from motor cortex, were shown to respond to visual stimuli, similar to the nearby cortical neurons in host visual cortex, suggesting that the grafted neurons become functionally integrated in a manner characteristic for each pyramidal neuron subtype. Overall, the capacity for the establishment of long-distance, targeted connectivity of ESC-derived cortical neurons appears quite similar to that obtained with fetal cortical tissue transplanted to the cortex in neonates or lesioned adult hosts (Gaillard \& Roger, 2000, Gaillard et al., 2007).

In our own work we have focused on the possibility to generate transplantable dopamine and striatal neurons from ESCs or iPSCs. Early experiments along these lines were successful in generation of TH-positive neurons from mouse and human ESCs and iPSCs, but the limited capacity of these cells to re-innervate appropriate denervated targets in the host brain suggested that most of the cells were incompletely specified and not of the appropriate midbrain phenotype. During embryonic development midbrain dopamine neurons are derived from floorplate cells, determined by timed interaction between SHH, FGF and WNT signaling (Bonilla et al., 2008, Ono et al., 2007). Based on these insights a new generation of protocols have been developed to derive midbrain floorplate-like cells from human ESCs and iPSCs, (Kirkeby et al., 2012, Kriks et al., 2011, Sundberg et al., 2013). These cells - characterised by their expression of two key transcription factors, FoxA2 and Lmx1A - survive transplantation and develop into fully mature TH-positive neurons without any signs of overgrowth or tumour formation. Importantly, the vast majority of these neurons express phenotypic markers characteristic of the two major midbrain dopamine neuron subtypes, the A9 neurons residing in the substantia nigra, and the A10 neurons located in the ventral tegmental area (Björklund \& Dunnett, 2007).

In adult 6-OHDA lesioned rats the TH-positive neurons generated by these protocols are highly efficient in re-innervating both $\mathrm{A} 9$ and $\mathrm{A} 10$ targets after transplantation, either into the striatum (Kirkeby et al., 2012, Kriks et al., 2011, Sundberg et al., 2013) or into the substantia nigra (Grealish et al., 2014). In the Grealish et al. (2014) study, the performance of the hESC-derived dopamine neuron precursors was compared with that of fetal human ventral midbrain (VM) dopamine neurons, obtained from 5.5 - 8 week old fetuses. The cells were transplanted unilaterally into the lesioned substantia nigra and axonal outgrowth was studied using antibodies directed against human NCAM and TH. Graft-derived axons could be traced in large numbers along the medial forebrain bundle and the nigrostriatal pathway to provide innervations in appropriate A9 and A10 targets, including striatum, nucleus accumbens, amygdala, olfactory tubercle and infra-limbic and 
cingulate cortex, reaching about $10 \mathrm{~mm}$ from the graft deposit. The axonal outgrowth was notably similar for both types of graft, and the functional potency - assessed as the minimal number of THpositive neurons necessary to induce a measurable functional effect - was similar for both cell preparations. Moreover, fibre density measurements showed that fetal and hESC-derived neurons had a similar propensity to innervate $\mathrm{A} 9$ and $\mathrm{A} 10$ targets, although the $\mathrm{A} 9$-specific innervation in the dorsolateral striatum was overall of higher density in rats with fetal VM grafts.

The functionality of the ESC-derived dopamine neurons is further supported by a study from Lorenz Studer's lab using optogenetics to modulate the activity of the grafted cells (Steinbeck et al., 2015). In this experiment, human ESC-derived dopamine neurons expressing the inhibitory, light-sensitive halo-rhodopsin chloride pump were transplanted to the striatum in immunodeficient, 6-OHDA lesioned mice. In the grafted mice, optogenetic silencing of the graft neurons was observed to reverse the recovered motor function to the level of the non-transplanted lesion controls. Further electrophysiological recording (in slices) showed that the graft-derived innervation exerted a modulatory action on glutamatergic synaptic transmission onto medium spiny striatal neurons, similar to that of the endogenous dopamine innervation, consistent with re-establishment of functional synaptic transmission.

The hESC-derived dopamine neurons generated in these protocols hold great promise for use in clinical trials: their properties are closely similar to the authentic dopamine neurons derived from human fetal VM, they can be generated in large numbers, and they survive and function just as well as fetal-derived VM neurons after transplantation without any signs of overgrowth or tumour formation. The ongoing efforts to explore their use in PD patients are discussed by Kirkeby et al., Studer et al. and Takahashi et al. in Chapter 7, 8 and 9.

\section{USE OF NEURAL TRANSPLANTS TO BRIDGE TRANSECTING LESIONS IN BRAIN AND SPINAL CORD.}

The idea for using neural tissue transplants to act as bridges to allow circuit repair arose out of studies on the more fundamental basic question of why do peripheral axons and pathways regenerate so much more effectively in the peripheral than in the central nervous system. The classic anatomical studies on nerve regeneration by Cajal and others (Cajal, 1928) described in exquisite detail the sprouting response, formation of new growth cones, and axon regeneration of axotomised DRG sensory and spinal motor axons along peripheral nerve paths to peripheral targets, and the slow restitution of peripheral sensory and motor function in time. By contrast, in the adult mammalian CNS, a similar initial sprouting is followed by abortive regeneration and dying back of the proximal axon (Cajal, 1928). The observation that regenerating dorsal root ganglia axons can grow long distances distally back to peripheral targets, but that proximal regeneration in the dorsal nerve root stops abruptly at the dorsal root entry zone transition between peripheral and central glia indicates clearly that the CNS / PNS discontinuity relates principally to the glial environment rather than to the regenerative capacity of central vs. peripheral neurons per se (Carlstedt et al., 1989).

Detailed analysis over three decades has highlighted a number of important differences between the central and peripheral growth environments, including the presence of different trophic and 
inhibitory factors; different glial populations providing different scarring responses; and expression of different basal lamina and surface adhesion molecules as substrates for stimulation, guidance and structural support of regenerating axons (Fawcett et al., 2001, Chew et al., 2012). Critically, in vitro co-cultures reveal that the principal peripheral myelinating glia, the Schwann cell, provides a far more effective substrate for neurite growth from both central and peripheral neurons than do the equivalent central glia, the oligodendrocyte (Bunge et al., 1988, Schwab \& Caroni, 1988). As noted in Section 2 above, it is more than a century since Tello first asked whether a graft of peripheral nerve might promote regeneration of motor axons to their peripheral targets (Tello, 1911). So, it was natural to ask whether similar grafts of sections of peripheral nerve, or preparations of their predominant Schwann cell glia might allow similar regeneration of central axons?

Pioneering experiments by Albert Aguayo and his team in Montreal, demonstrated this possibility, and opened the way for promoting long distance axon growth in the CNS, as in the PNS. An initial approach to spinal cord injury was to insert, in rats, a piece of seural nerve into the cavity formed by complete transection of the mid-thoracic spinal cord (see Figure 4A). HRP injections into the proximal or distal cord stumps revealed effective labelling of host neurons on the other side of the transection, indicating regrowth of the central axons through the peripheral bridge (Richardson et al., 1980, Richardson et al., 1982). An alternative approach, which has attracted particular attention was undertaken by David and Aguayo (1981). They implanted a 35mm long segment of peripheral nerve extra-spinally in the subcutaneous tissues along the back, so as to provide a bridge with the proximal end inserted into the medulla and the distal end at a mid thoracic level (Figure 4B). At post mortem 6 months later, the peripheral nerve grafts were then cut within the extraspinal zone and HRP crystals applied to the cut ends to trace host axons projecting into and through the grafts. Many retrogradely-labelled host neurons were observed within both the medulla and distal spinal cord, typically over a $4-6.5 \mathrm{~mm}$ band close to the site of nerve root insertion. Moreover, anterograde labelling of host axons was also observed extending from the nerves in both medulla and distal spinal cord, but typically extending no more than $2 \mathrm{~mm}$ into the host neuropil (David \& Aguayo, 1981). Thus adult central neurons can regenerate long distances through a peripheral nerve grafts (in both ascending and descending directions), but the regenerating axons failed to show any comparable long-distance axon growth once they re-enter the adult host spinal cord environment. Thus a key challenge for effective spinal cord regeneration will be not only how to deliver long distance growth of regenerating or replaced neurons to innervate distal targets, but also how to promote appropriate reinnervation and effective long-distance extension of the regenerating axons, at least within large or extended target zones.

Insert Figure 4 about here

The use of the principle axon-ensheathing and myelinating glial cells of the PNS, the Schwann cell, to promote central regeneration in spinal cord injury has been an active and productive topic of investigation over the last 30 years, a project pioneered by Richard and Mary Bunge and their colleagues at the Miami Centre. Their programme has focussed on isolating Schwann cells and to refine preparation methods to achieve scaring free integration with the host spinal cord in partial and complete transection models (Figure 4A), and to deliver the most effective substrates for axon regeneration (Bunge \& Wood, 2012). In chapter 18, Mary Bunge and colleagues provide a recent 
update of the origins and recent refinements of the cell preparation protocols, the comparison of the capacity for regenerative support provided by human vs rat Schwann cells, and the development of a translational pathway towards clinical application. Following a similar theme, a number of laboratories are now seeking to generate an equivalent Schwann cell-like cell for human transplantation from stem cell starting materials (Dulin \& Lu, 2014) and in chapter 14 Paul Lu discusses the first attempt to deliver stem cell-derived glial transplants to clinical application in spinal cord injury.

A fourth alternative strategy to bridging spinal cord injury is found in the work of Raisman and colleagues aimed to identify an alternative source of readily accessible regeneration-promoting glial cells. Li, Field and Raisman found that transplants of olfactory ensheathing cells (OECs) cultured from rat olfactory bulb placed into small lesion cavities in the spinal cord could effectively bridge the lesions, promoting efficient regeneration of central axons through the graft (Li et al., 1997, Li et al., 1998). The interesting feature of this population of glial cells is that they can potentially be harvested via a trans-nasal route from a living human adult donor for use in allotransplantation (Li et al., 1997, Raisman, 2001). In experimental animals, a systematic series of studies have subsequently evaluated the functional efficacy of such grafts in tests of forelimb motor reaching (Li et al., 1997, Keyvan-Fouladi et al., 2003), breathing and climbing (Li et al., 2003). These studies have led on to an initial clinical trial in which autologous OECs from a nasal mucosa biopsy have been transplanted into the spinal cord cavity in 6 patients with chronic mid thoracic paraplegia. The initial results show that this approach is feasible and safe, with some imaging evidence of white matter fibre tract regrowth, and some sparse functional recovery at 1 year (Tabakow et al., 2013).

In parallel, Ibrahim et al (2014) have explored the use of OECs derived from the olfactory bulb itself, rather than from the olfactory mucosa, using a keyhole surgical approaches to source the cells from the transplant recipient themselves (Czyz et al., 2014, 2015). Results in a first patient transplanted with autologous olfactory bulb cells are looking particularly promising in reporting detectable recovery of voluntary movements and partial recovery of sensation in the lower limbs. Interestingly, transplantation in this patient was accompanied by intensive and extended pre- and post-operative rehabilitation (see chapter 13 by Clinch, Busse and colleagues).

Nevertheless, although these positive observations are accompanied by indications of reformation of white matter connectivity, as assessed by MR imaging, the mechanisms by which any functional changes are achieved remain uncertain (Keyvan-Fouladi et al., 2002). Thus, OECs may contribute a bridging substrate for host axon regeneration, and also contribute to peripheral-type remyelination and a broad range of trophic influences. Moreover, recovery depends on at least a few host corticospinal fibres spared by the lesion as a source of extensive sprouting and synaptic reorganisation (Keyvan-Fouladi et al., 2002). When comparing bulbar and mucosal grafts in a rat rhizotomy paradigm, it was noteworthy that both graft types exhibited recovery in paw reaching, even though the latter grafts did not survive (Ibrahim et al., 2014). Similarly, in the spinal cord transection model rejection of the graft did not abolish the recovered function, although in this situation the grafts had survived long enough for host axon bridging to have been established (Li et al., 2016). More than anything else, these studies highlight the degree to which the establishment and maintenance of functional recovery involves a complex array of interacting mechanisms, such than any opportunity for clinical translation depends on the precise selection of the cells, methods and timing of surgical intervention and interaction with the host environment. 
Similar bridging strategies have been used in brain, using glial cells to provide guidance channels for promoting regeneration of central axons over long distances or within a central environment that would not normally support such endogenous regeneration (from axotomised host neurons) or exogenous growth (from transplanted replacement neurons). Thus, for example, we have engaged in seeking to promote regeneration of the nigrostriatal pathway. Initial studies of proof of principle were undertaken in the standard unilateral 6-OHDA lesion model in which solid VM grafts were positioned at midbrain level on the surface of the superior colliculus in combination with a peripheral sciatic nerve that bridged the $2-3 \mathrm{~cm}$ gap to the denervated host striatum (Figure 4C). Post mortem TH immunohistochemistry indicated extensive TH-positive fibre growth from dopaminergic neurons with the grafts, throughout the length of the peripheral nerve bridge, to sprout and provide local terminal ramification in the host striatum (Aguayo et al., 1984). Such grafts were seen to be competent to alleviate amphetamine-induced rotation, albeit over a slower time course than achieved with intrastriatal VM graft placement (Aguayo et al., 1984, Gage et al., 1985). Importantly behavioural recovery was abolished by making a cut of the peripheral nerve, indicating the importance of the bridge-graft mediated reinnervation for its functional efficacy.

In order to refine the nigrostriatal bridge model we introduced an alternative intracerebral grafting strategy, laying down the bridge cells by an oblique injection along a direct track between the substantia nigra and the striatum (See Figure 4D; Dunnett et al., 1989). In the first study, the combination of intranigral VM grafts with alternative nigrostriatal bridges comprising astrocytes or laminin-based substrates were ineffective, and although bridges of striatal (WGE) neurons did stimulate axon ingrowth the grafts were full of terminal ramifications with only few axons extending as far as the striatum. A far more effective cell source for the bridges, as predicted by the studies in spinal cord outlined above, was the use of cultured Schwann cells, in particular when modified to express specific trophic factors on which DA neuron survival is dependent, FGF and GDNF. These engineered Schwann cell bridges promoted extensive outgrowth of TH positive axons from dopamine neurons within the intranigral VM grafts over $10-15 \mathrm{~mm}$ to the 6-OHDA lesioned striatum (Wilby et al., 1999, Brecknell et al., 1996b). In a related study, in which the lesions were made not by the toxin 6-OHDA (which kills the nigral neurons), but by a knife cut lesion (which transects the axons leaving the nigral neurons themselves largely intact) the oblique Schwann cell bridge was seen to stimulate axon regeneration of the endogenous axotomised host nigral cells to enable a more extensive reinnervation of the denervated striatum (Brecknell et al., 1996a).

A final distinction we may draw is the one between "passive" and "active" bridges. In an early review of spinal cord transplantation, Barbara Bregman (1994) highlighted how transplants of spinal cord tissue into a cord transection cavity can serve both as a 'bridge' and as a 'relay'. The former situation was seen most often in immature rats, whereby host axons were seen to grow through the neural transplant and back into the distal host cord, much as described above for the peripheral bridges of David and Aguayo (David \& Aguayo, 1981). Conversely, in adulthood, host axons would innervate a spinal cord graft, making potential contacts with the grafted spinal cord neurons, which in turn grew back into the distal cord, providing a relay of communication across the site of injury (Bregman et al., 1993). In support of this idea subsequent studies have confirmed a synaptic basis of the relay (White et al., 2010, Bonner et al., 2011).

The concept of "passive" and "active" bridges have been explored also in the septo-hippocampal system. Kromer et al (1981) and Wendt et al. (1983) made use of transplants of either fetal hippocampal tissue, or a piece of peripheral nerve, to provide a bridge across a lesion cavity 
transecting the fimbria-fornix pathway (see Figure 4E,F). AChE-positive cholinergic axons, were seen to regenerate in large numbers from the septum into the graft, and some of them extended also across the graft-host border into the denervated hippocampus. In a subsequent study, Kawaja et al. (1992) showed that the capacity to promote regeneration of the host septo-hippocampal pathway, across the lesion and into the host hippocampus, was greatly promoted by grafts of fibroblasts engineered to secrete NGF. The alternative approach to create an "active" relay bridge has been explored by Nilsson and colleagues in studies of cholinergic and noradrenergic neuron transplants (see Figure 4E,F). As described above in Section 4, grafts of embryonic cholinergic or noradrenergic neurons implanted into the fimbria-fornix lesion cavity, adjacent to the denervated hippocampus provide rich transmitter specific patterns of reinnervation of the target. Using microdialysis, Nilsson et al, (1990c) found that acetylcholine release from graft-derived neurons in the hippocampus was under precise regulation of the host brain, which was shown by anatomical tracing and immunohistochemistry to be due to rich regulatory ingrowth of brainstem, hypothalamic and septaldiagonal band neurons into the grafts.

The theme of relay bridging has received renewed attention recently with the investigation of alternative stem cell-derived neurons for transplantation in spinal cord injury. Again, there is growing evidence that grafts of neurons differentiated to spinal cord-like fates can integrate into the site of spinal cord injury with both afferent and efferent connections with the host CNS (Lu et al., 2012), indicating a functional benefit by relaying ascending as well as descending connections through the grafts, to and from the brainstem (Dulin \& Lu, 2014).

It should be noted that, in terms of mechanism, the 'active' or 'relay' bridges described above, establishing afferent and efferent connections within the host brain, are not fundamentally dissimilar to the reciprocal graft-host connectivity and integration into the host neural circuitry described for striatal grafts as the basis for true 'brain repair'. To the extent that a distinction can be drawn, it relates to the graft being seen as providing a relay of host information across the graft in the former case, vs. the graft providing an additional transformation of that information through local circuit processing before its relay onwards in the latter case. These alternative modes of action are not mutually exclusive, but reflect complex interactions between grafted cells and host tissues that need full separate analysis in each particular case.

\section{PROSPECTS FOR TRANSLATION TO CLINICAL APPLICATIONS}

The first report of successful clinical neural transplantation was published over 25 years ago (Lindvall et al., 1990), and the previous 3 volumes in this series - 1994, 2000 and 2012 - were all published in the context of the clinical realisation of the basic experimental science, and the core principles of how grafts work and how to make them work better were already appreciated (Dunnett \& Björklund, 1994b). Nevertheless, the enthusiastic consideration of a broad range of other disease applications discussed in 1994 (Dunnett \& Björklund, 1994a), was tempered by slow progress in 2000 (Dunnett \& Björklund, 2000), and the challenges raised by the first failed randomised controlled PD trials in the early 2000s (Freed et al., 2001, Olanow et al., 2003) slowed progress still further with little in the way of progress toward additional clinical targets achieved by 2012 (Dunnett \& Björklund, 2012). 
However, the Zeitgeist has improved considerably in the last 5 years. A number of critical analyses have led to a better understanding of the weaknesses in the design of the two failed NIH trials, and why even encouraging results were so negatively interpreted (Barker, 2003, Wijeyekoon \& Barker, 2009). In Parkinson's disease, reanalysis of the preceding data on a multicentre scale has highlighted key features of trial design that need to be addressed in order to have a chance of revealing significant therapeutic benefit. This includes more careful selection of patients, delivery and distribution of cells transplantation, effective immunosuppression, and design of multidimensional functional and surrogate outcomes (Piccini et al., 2005, Allan et al., 2010).

As highlighted in the chapter by Kirkeby et al. in this volume (Chapter 7), this field is now reinvigorated by the development of stem cell based alternatives for cell therapy in PD. As reviewed in the chapter by Lorenz Studer, his group is one of several teams worldwide to have developed effective protocols for differentiating human pluripotent stem cells to midbrain dopamine neurons, which are functionally equivalent to authentic embryonic dopamine cells according to multiple behavioural, physiological and molecular criteria (Kriks et al., 2011, Pfisterer et al., 2011, Kirkeby et al., 2012). As reviewed in Section 2, these cells function appropriately in the relevant animal models, , and the 'NYSTEM' programme led by Lorenz Studer in New York is now well advanced towards the first-in-man clinical trial in PD patients. Parallel programmes are already following on including 'Stem-PD' coordinated by Roger Barker in Europe; and the CiRA trial coordinated by Jun Takahashi in Kyoto, Japan, based on an alternative cell source, i.e., DA neurons differentiated from human iPS cells. These initiatives are discussed further in Chapter 7, 8 and 9 in this volume.

Encouragingly, and in contrast to previous competitiveness, the new PSC-derived cell therapy era is marked by a remarkable degree of cooperation through the newly-formed 'Gforce-PD' network, to address common standards of regulation, experimental design and sharing of reagents, tools and assessment protocols, so that even if cell sources and transplant methods may differ the trial outcomes will be comparable according to common standards and measures (Barker et al., 2015).

As in PD, so also in HD. Following initial reports of positive outcomes in individual cases from at least 4 centres (Bachoud-Lévi et al., 2000, Reuter et al., 2008, Paganini et al., 2014, Hauser et al., 2002), and follow up of benefit lasting at least 6 years (Bachoud-Levi et al., 2006), scale up to larger trials has been slower to realise. The logistic difficulties based on sourcing adequate supplies of fetal tissues of suitable quality and standardisation has been challenging, and the one large multicentre French cohort, started in 2003 is still to complete and report. Again, the rapid advances in stem cell science have led to recent publications of reliable protocols for differentiating both MSN projection neurons and striatal interneurons from both hES and hiPS cell sources (Evans et al., 2012, Precious \& Rosser, 2012, Arber et al., 2015). These cells survive transplantation, integrate into the host brain with the grafts expressing both DARPP32-positive MSN and interneuronal phenotypes (Shin et al., 2012, Delli Carri et al., 2013, Arber et al., 2015). Although, to date, at best modest functional benefit has been reported following stem cell grafting in the quinolinic acid lesion model (Delli Carri et al., 2013), the conditions for effective cell transplantation in HD are increasingly well understood (Freeman et al., 2011, Rosser et al., 2011), and a major multicentre collaborative effort, 'Repair-HD', is underway to develop striatal projection and interneuronal derivation towards a first-in man clinical trial (Dascher-Nadel et al., 2014).

The flexibility, availability and potentials for standardisation and quality control offered by stem cell derivation of transplantable neuronal populations, exemplified above for PD and HD, is opening the way for the first time for applications in a much broader range of clinical indications. While 
recognising the worrying proliferation of 'stem cell tourism' clinics offering entirely unproven (albeit, expensive and highly profitable) cell therapies around the world, the majority of which are entirely spurious (Kiatpongsan \& Sipp, 2009, Daley et al., 2016), there is nevertheless a parallel rapid growth in credible science (which this volume seeks to capture) seeking to lay the experimental foundations for more science-driven applications based on defined protocols for differentiation of specific cell types for each clinical application.

So how can a credible therapy be distinguished from a spurious one? Recent guidelines provided by the ISSCR (Daley et al., 2007, Daley et al., 2016) are important but can be difficult to apply in an individual situation without inside knowledge and expertise. As outlined in Section 5 above, a key consideration must be to provide an understanding of the mechanism by which the stem cell therapy is expected to yield functional benefit. Moreover pre-clinical validation must include clear experimental evidence that the transplantation intervention works in an appropriate model of disease, and that it does so by the hypothesised mechanism(s). In a review for the EuroStemCell consortium, Roger Barker (2013) considers that a potential new stem cell therapy should meet four criteria:

- "(the) stem cells can make authentic replacement neurons of the type you want (nigral dopamine cells with PD; striatal DDARP-32 projection striatal neurons in Huntington's Disease etc);

- the properties of these stem-cell derived neurons can be reproducibly demonstrated in the laboratory (and ideally more than just one laboratory), both in the dish and in animal models of disease;

- the neurons can survive long term in animal models of disease and have functional benefits to that animal; and

- all of this can be done without evidence of cell overgrowth or transformation into malignant (cancerous) cells within the transplant."

We now see a wide range of new applications under active investigation, including the development of stem cell derived neurons for stroke, multiple sclerosis, epilepsy, ALS/motor neuron disease, spinal cord injury, traumatic brain injury (concussion, impact, and penetrating brain wounds), brain cancers and rare monogenic metabolic disorders. Several of these approaches are considered in later chapters of this volume. For some of the cited applications there is a rational mechanism for repair, for most, however, the pre-clinical data are still not sufficiently convincing to warrant progression to a clinical trial. A good example, where the underlying experimental validation is sufficiently clear, relates to the application of surgical replacement of the supportive retinal pigment epithelium in eye diseases related to macular degeneration. Several groups have now developed effective protocols for differentiation of PSCs to a retinal pigment epithelium cell phenotype (Buchholz et al., 2013), and at least three stem cell-based cell therapies are underway in USA, Japan and the UK. Injection of hPSC-RPE suspensions have not achieved optimal functionally integration. However, with good preclinical evidence of efficacy, seeding the cells on an artificial matrix to provide transplantable monolayer sheets are now entering clinical trial in the 'London Project to Cure Blindness' (Ramsden et al., 2016), as described by Peter Coffey (Chapter 22) in this volume.

These trials are still at a very early stage. However as we go to press, there is considerable and widespread optimism - albeit, as yet unproven - that the neural transplantation field is at a stage of transition from long-lasting but uncritical promise, to the advent of a new era of effective, evidencebased cell therapies for a broad range of hitherto untreatable neurodegenerative diseases and 
conditions. Only time and evidence, based on high quality critical science, will establish whether such optimism is justified.

\section{Acknowledgements}

Our own studies are funded by the UK and Swedish Medical Research Councils, and participation in the EU FP7 Transeuro, repair-HD, NeuroStemCell and NeuroStemCellRepair consortia. 


\section{Tables}

Table 1. Mechanisms of Graft Function of Greater or Lesser Neuronal Specificity.

\begin{tabular}{|c|c|c|}
\hline & Mechanism & Explanation \\
\hline 1. & $\begin{array}{l}\text { Nonspecific or negative } \\
\text { effects of surgery }\end{array}$ & $\begin{array}{l}\text { Surgical, mechanical or traumatic injury caused by the implantation } \\
\text { surgery including space occupying lesions and transplant overgrowth }\end{array}$ \\
\hline 2. & $\begin{array}{l}\text { Positive effects of surgical } \\
\text { lesions * }\end{array}$ & $\begin{array}{l}\text { Surgical damage (rarely) provides a positive effect, such as provided by the } \\
\text { 'rebalancing' of output pathways following lesions or deep brain } \\
\text { stimulation in Parkinson's disease }\end{array}$ \\
\hline 3. & Bystander effects * & $\begin{array}{l}\text { Non-neuronal effects, esp. of undifferentiated stem cells, to reduce scar } \\
\text { formation, promote neuroprotection and modulate the immune } \\
\text { environment. }\end{array}$ \\
\hline 4. & Trophic stimulation & $\begin{array}{l}\text { Implants deliver exogenous trophic factors that enhance neuronal survival } \\
\text { plasticity, axon sprouting and regeneration within host neurons. }\end{array}$ \\
\hline 5. & $\begin{array}{l}\text { Target support of host } \\
\text { projections }\end{array}$ & $\begin{array}{l}\text { Implanted tissues provide new or replacement targets for host axons, } \\
\text { preventing die back following endogenous target loss. }\end{array}$ \\
\hline 6. & Structural glial support * & $\begin{array}{l}\text { Glial cell replacement provides structural, metabolic and functional } \\
\text { support for endogenous or exogenous neuronal networks. }\end{array}$ \\
\hline 7. & Pharmacological & $\begin{array}{l}\text { Diffuse release of deficient neurotransmitters, hormones or signalling } \\
\text { molecules acting at tonic levels on host neurons. }\end{array}$ \\
\hline 8. & Diffuse reinnervation & $\begin{array}{l}\text { Implanted cells establish synaptic contacts with host targets, with synaptic } \\
\text { release of deficient neurotransmitters at physiological concentrations, and } \\
\text { with potential of local presynaptic feedback regulation. }\end{array}$ \\
\hline & Passive bridges & $\begin{array}{l}\text { Cellular grafts provide substrates for stimulation and guidance of axonal } \\
\text { (re-)growth, across lesions, from host or graft neurons. }\end{array}$ \\
\hline 10 & . Active bridges & $\begin{array}{l}\text { Grafted neurons provide a trans-synaptic relay of communication between } \\
\text { host targets }\end{array}$ \\
\hline & $\begin{array}{l}\text { Reciprocal graft-host } \\
\text { reinnervation }\end{array}$ & $\begin{array}{l}\text { Implanted neurons become incorporated into the host neuronal network } \\
\text { to restore information processing capacity beyond simple relay. }\end{array}$ \\
\hline 12 & Full reconstruction & $\begin{array}{l}\text { Reconstruction of all aspects of the damaged host network for full } \\
\text { restoration and repair of normal circuit processes. }\end{array}$ \\
\hline
\end{tabular}

Based on table in Dunnett and Bjorklund, Neural Transplantation (Dunnett \& Björklund, 1994b), see text for examples

* Italics: Mechanism added subsequent to the 1994 table. 


\section{Figure legends}

Figure 1. Schematic illustration of denervation and circuit repair in ectopic 6-OHDA/VM lesion/graft model and in the homotopic EAA/WGE model. Abbreviations: 6-OHDA, 6hydroxydopamine; $\mathrm{CPu}$, caudate-putamen ('striatum'); Ctx, neocortex; EAA, excitotoxic amino acid; GP, globus pallidus; NSP, nigrostriatal pathway; SN, substantia nigra; VM, ventral mesencephalon; WGE, whole ganglionic eminence.

Figure 2. Behavioural and physiological evidence of relearning and long term plasticity. A, schematic diagram of the 9-hole box operant test apparatus. B, initial acquisition of lateralised choice reaction time task, performance abolished by striatal lesions, and relearned in the presence of an established transplant (Brasted et al., 1999c, Brasted et al., 1999b). C, schematic diagram of the oblique brain slice used to record synaptic plasticity at the corticostriatal graft-host synapse. D, comparable LTD at the corticostriatal synapse in both intact and grafted striatum. E, transformation to LTP in both groups in Mg-free media. Similar patterns of long term plasticity were described using both extracellular and intracellular recordings (Mazzocchi-Jones et al., 2009).

Figure 3. Fiber outgrowth from fetal cholinergic neurons transplanted to the hippocampus in adult rats. The tissue was obtained from the basal forebrain of E16 rat embryos and transplanted either as a solid piece into a pre-formed cavity transecting the fornix-fimbria (FF) pathway (A), or as a cell suspension injected into the dorsal and ventral hippocampus (B). C. Acetylcholinesterase (AChE) staining of the normal hippocampal innervation, loss following fimbria fornix lesion, and extensive reinnervation in laminar specific distribution by a solid septal graft. D. Functional recovery in T maze learning associated with solid and suspension grafts in the hippocampus. E. Photomicrographs of AChE staining showing that the distribution and laminar patterning of the graft-derived fibers in hippocampus and dentate gyrus (right panel) match closely the normal laminar innervation patters (left). Data derived from (Björklund \& Stenevi, 1977, Dunnett et al., 1982, Nilsson et al., 1990a). See text for further details.

Figure 4. Bridge models. Schematic illustration of alternative strategies for bridge grafting. $A, B$, in the spinal cord. $\mathbf{C , D}$, in the nigrostriatal pathway. $\mathbf{E}, \mathbf{F}$, in the septo-hippocampal circuit. See text for further details. 


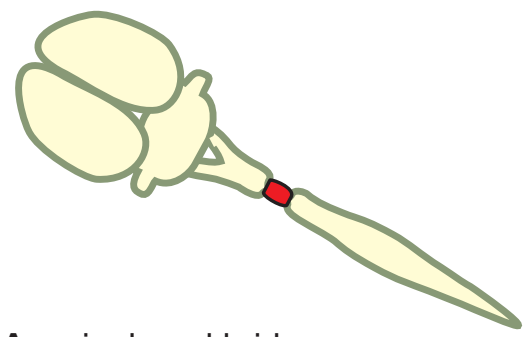

A. spinal cord bridge

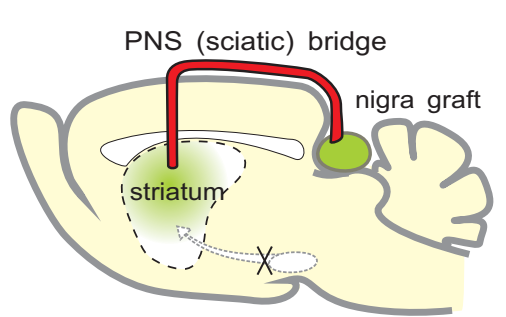

C. extracerebral PNS bridge

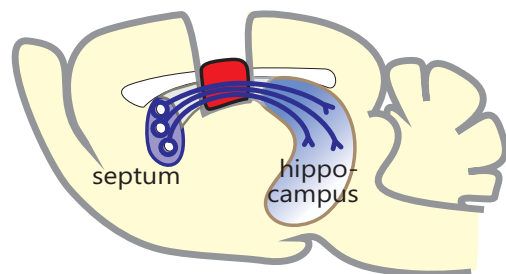

E. "passive" bridge graft

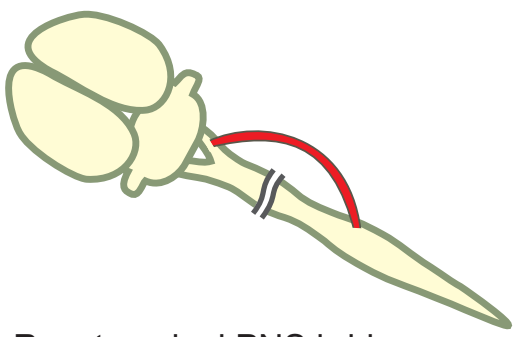

B. extraspinal PNS bridge

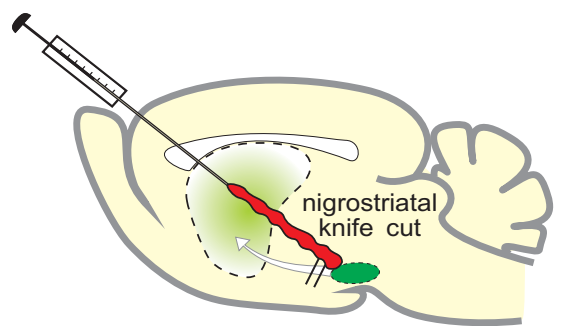

D. intracerebral suspension bridge

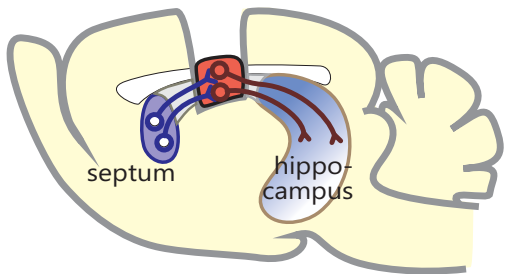

F. "active" bridge graft 
A

Single-stage cavity

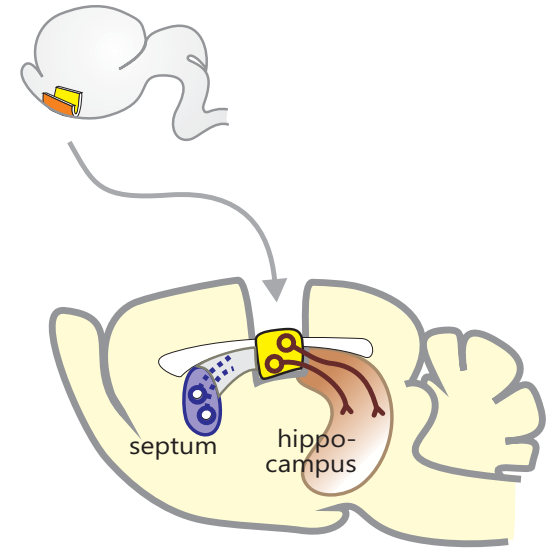

FF-lesion +
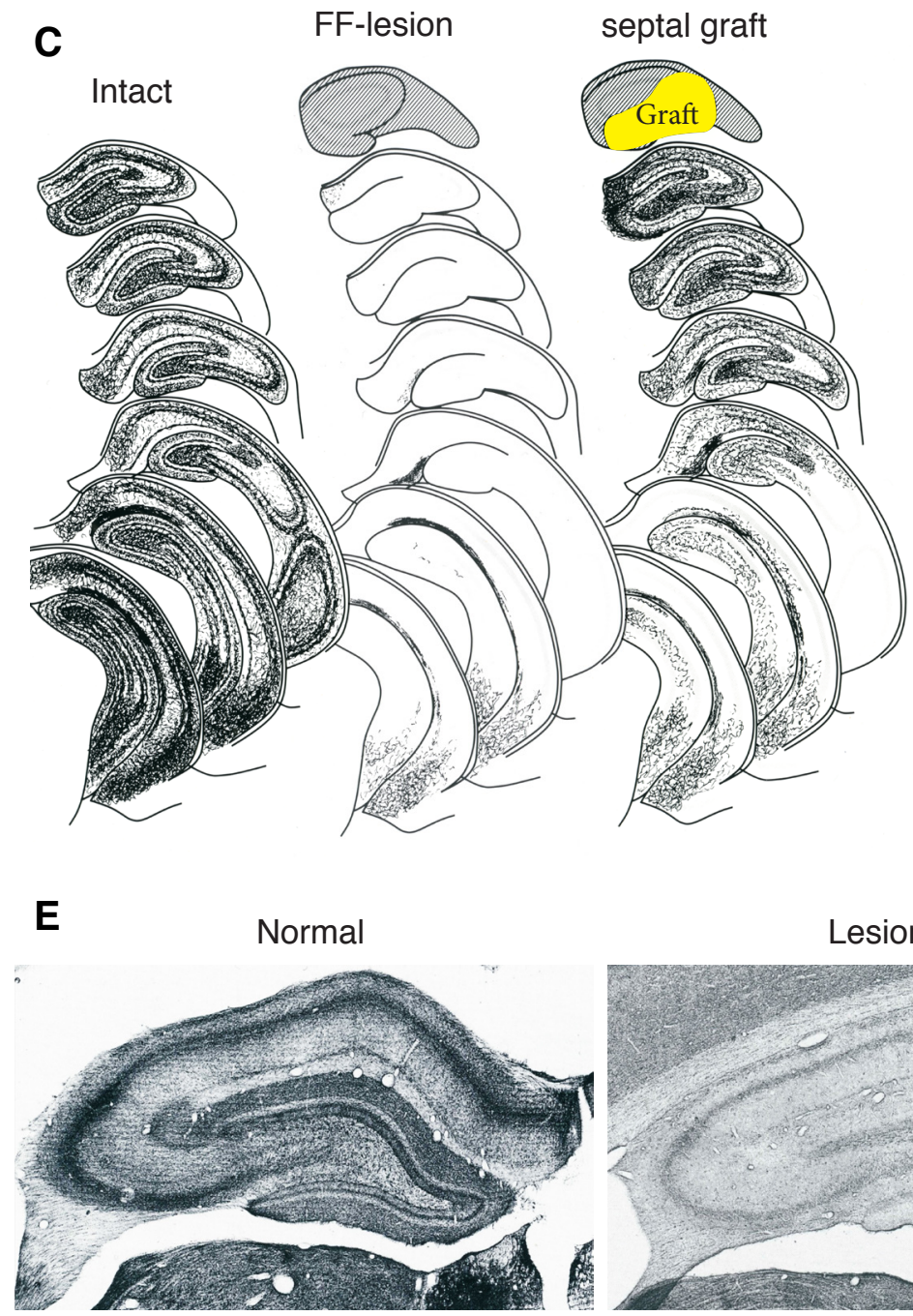

B Standard septal cell suspension

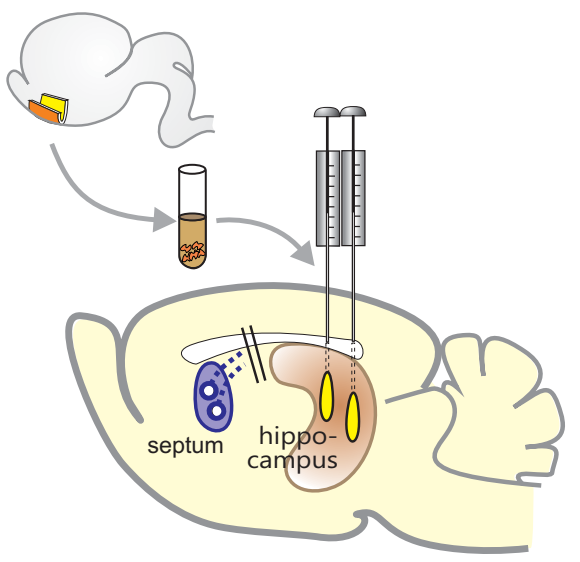

D

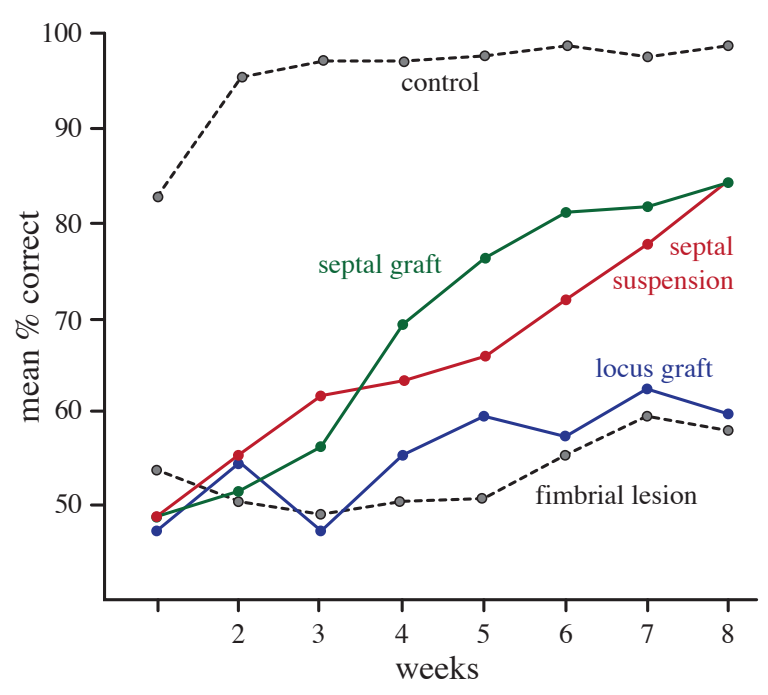

E

Normal

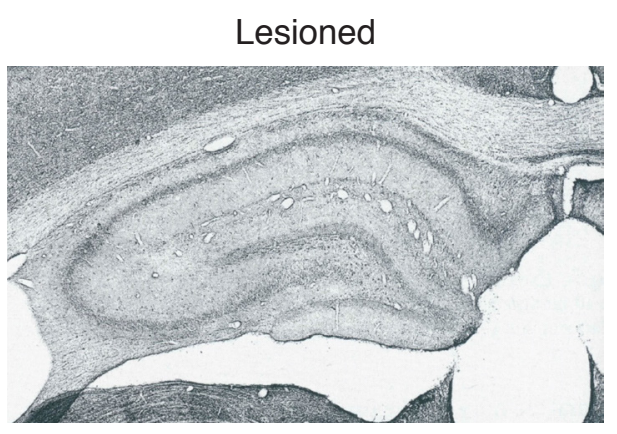

Grafted

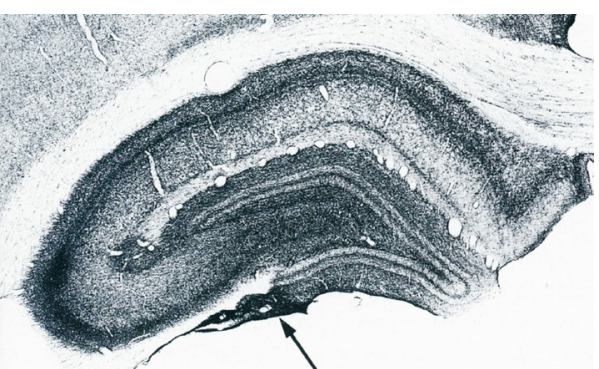


A. Operant '9-hole' box

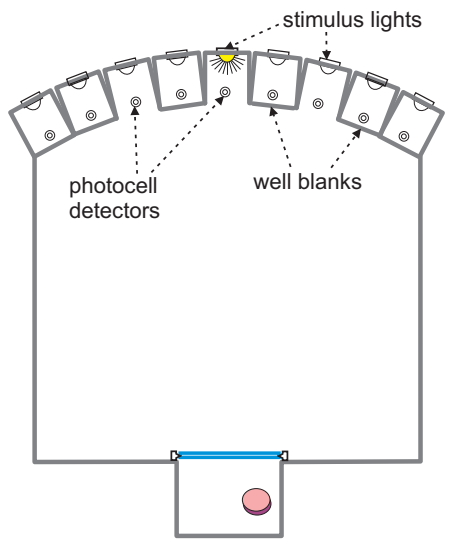

C. Oblique corticostriatal slice

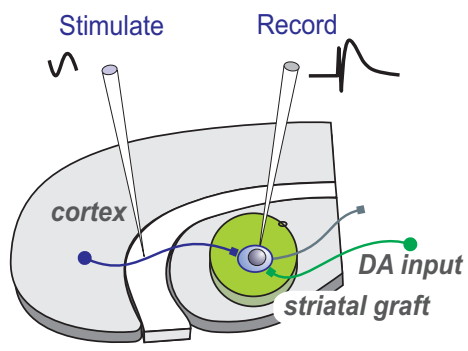

B. Learning to use the transplant

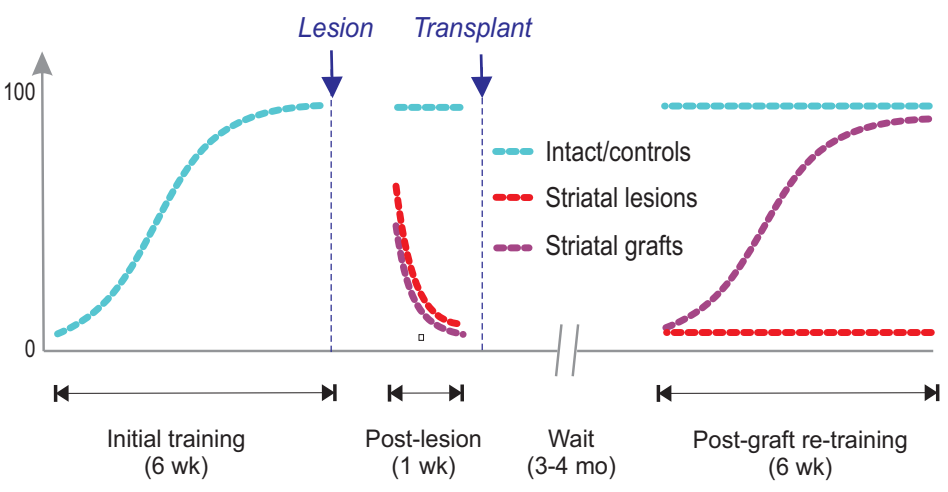

D. LTD in standard media

E. LTP in $\mathrm{Mg}^{2+}$-free media

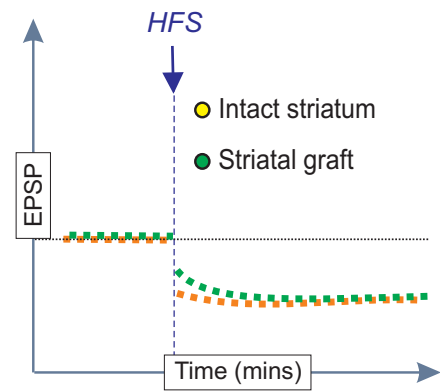


A. Intact

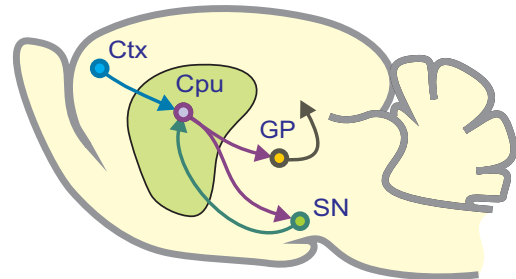

B. 6-OHDA NSP lesion

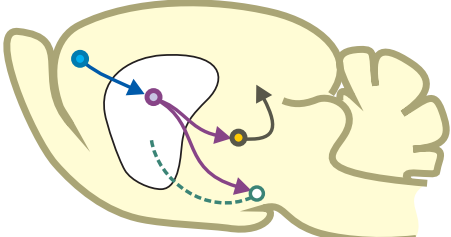

C. VM (nigral) graft

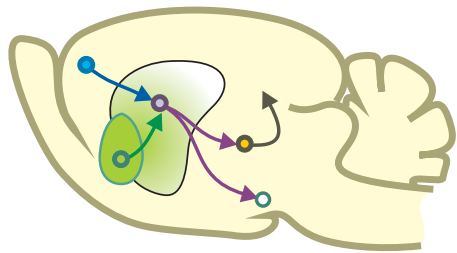

D. EAA striatal lesion

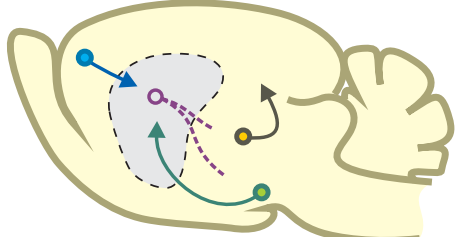

E. WGE (striatal) graft

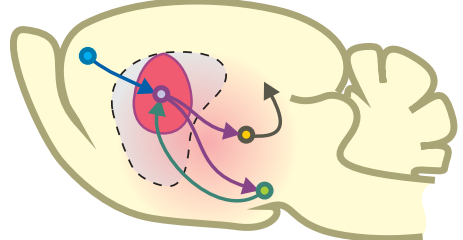




\section{References}

13. Aguayo, A.J., Björklund, A., Stenevi, U., Carlstedt, T. 1984. Fetal mesencephalic neurons survive and extend long axons across peripheral nervous system grafts inserted into the adult rat striatum. Neurosci. Lett., 45, 53-58.

14. Aihara, N., Mizukawa, K., Koide, K., Mabe, H., Nishino, H. 1994. Striatal grafts in infarct striatopallidum increase GABA release, reorganize $\mathrm{GABA}_{\mathrm{A}}$ receptor and improve water-maze learning in the rat. Brain Res. Bull., 33, 483-488.

15. Alberch, J., Pérez-Navarro, E., Canals, J.M. 2002. Neuroprotection by neurotrophins and GDNF family members in the excitotoxic model of Huntington's disease. Brain Res. Bull., 57, 817-822.

16. Allan, L.E., Petit, G.H., Brundin, P. 2010. Cell transplantation in Parkinson's disease: problems and perspectives. Curr. Opin. Neurol., 23, 426-432.

17. Alvarez-Dolado, M., Calcagnotto, M.E., Karkar, K.M., Southwell, D.G., Jones-Davis, D.M., Estrada, R.C., et al. 2006. Cortical inhibition modified by embryonic neural precursors grafted into the postnatal brain. J. Neurosci., 26, 7380-7389.

18. Arber, C., Precious, S.V., Cambray, S., Risner-Janiczek, J.R., Kelly, C.M., Noakes, Z., et al. 2015. Activin A directs striatal projection neuron differentiation of human pluripotent stem cells. Development, 142, 1375-86.

19. Armstrong, R.J.E., Hurelbrink, C.B., Tyers, P., Ratcliffe, E.L., Richards, A., Dunnett, S.B., et al. 2002. The potential for circuit reconstruction by expanded neural precursor cells explored through porcine xenografts in a rat model of Parkinson's disease. Exp. Neurol., 175, 98-111.

20. Bachoud-Levi, A.C., Gaura, V., Brugieres, P., Lefaucheur, J.P., Boisse, M.F., Maison, P., et al. 2006. Effect of fetal neural transplants in patients with Huntington's disease 6 years after surgery: a long-term follow-up study. Lancet Neurol., 5, 303309.

21. Bachoud-Lévi, A.C., Rémy, P., Nguyen, J.P., Brugières, P., Lefaucheur, J.P., Bourdet, C., et al. 2000. Motor and cognitive improvements in patients with Huntington's disease after neural transplantation. Lancet, 356, 1975-1979.

22. Bacigaluppi, M., Pluchino, S., Peruzzotti, J.L., Kilic, E., Kilic, U., Salani, G., et al. 2009. Delayed post-ischaemic neuroprotection following systemic neural stem cell transplantation involves multiple mechanisms. Brain, 132, 2239-2251.

23. Baraban, S.C., Southwell, D.G., Estrada, R.C., Jones, D.L., Sebe, J.Y., Alfaro-Cervello, C., et al. 2009. Reduction of seizures by transplantation of cortical GABAergic interneuron precursors into Kv1.1 mutant mice. Proc. Natl. Acad. Sci. U.S.A., 106, 15472-15477.

24. Barkats, M., Nakao, N., Grasbon-Frodl, E.M., Bilang-Bleuel, A., Revah, F., Mallet, J., et al. 1997. Intrastriatal grafts of embryonic mesencephalic rat neurons genetically modified using an adenovirus encoding human $\mathrm{Cu} / \mathrm{Zn}$ superoxide dismutase. Neuroscience, 78, 703-713.

25. Barker, R.A. 2003. Porcine neural xenografts for the treatment of neurodegenerative diseases. Lancet Neurol., 2, 443-444.

26. Barker, R.A. 2013. Stem cell therapies and neurological disorders of the brain: what is the truth? EuroStemCell website, http://www.eurostemcell.org/commentanalysis/stem-cell-therapies-andneurological-disorders-brain-what-truth. 
27. Barker, R.A., Studer, L., Cattaneo, E., Takahashi, J., Consortium, G.-F.P. 2015. GForce PD: a global initiative in coordinating stem cell-based dopamine treatments for Parkinson's disease. npj Parkinson's Disease, 1, 15017: 1-5.

28. Björklund, A., Campbell, K., Sirinathsinghji, D.J.S., Fricker, R.A., Dunnett, S.B. 1994. Functional capacity of striatal transplants in the rat Huntington model. In: Dunnett, S.B., Björklund, A. (eds.) Functional Neural Transplantation. New York: Raven Press, pp 157-195.

29. Björklund, A., Dunnett, S.B. 2007. Dopamine neuron systems in the brain: an update. Trends Neurosci., 30, 194-202.

30. Björklund, A., Dunnett, S.B., Stenevi, U., Lewis, M.E., Iversen, S.D. 1980. Reinnervation of the denervated striatum by substantia nigra transplants: functional consequences as revealed by pharmacological and sensorimotor testing. Brain Res., 199, 307-333.

31. Björklund, A., Kromer, L.F., Stenevi, U. 1979. Cholinergic reinnervation of the rat hippocampus by septal implants is stimulated by perforant path lesion. Brain Res., 173, 57-64.

32. Björklund, A., Lindvall, O., Isacson, O., Brundin, P., Wictorin, K., Strecker, R.E., et al. 1987. Trends Neurosci., 10, 509-516.

33. Björklund, A., Nilsson, O.G., Kalén, P. 1990. Reafferentation of the subcortically denervated hippocampus as a model for transplant-induced functional recovery in the CNS. Prog. Brain Res., 83, 411-426.

34. Björklund, A., Stenevi, U. 1977. Reformation of the severed septohippocampal cholinergic pathway in the adult rat by transplanted septal neurons. Cell and Tissue Research, 185, 289-302.

35. Björklund, A., Stenevi, U. 1979. Reconstruction of the nigrostriatal dopamine pathway by intracerebral transplants. Brain Res., 177, 555-560.

36. Björklund, A., Stenevi, U. 1985a. Intracerebral neural grafting: a historical perspective. In: Björklund, A., Stenevi, U. (eds.) Neural Grafting in the Mammalian CNS. Amsterdam: Elsevier, pp 3-14.

37. Björklund, A., Stenevi, U. (eds.) 1985b. Neural Grafting in the Mammalian CNS, Amsterdam: Elsevier.

38. Björklund, A., Stenevi, U., Schmidt, R.H., Dunnett, S.B., Gage, F.H. 1983. Intracerebral grafting of neuronal cell suspensions. II. Survival and growth of nigral cell suspensions implanted in different brain sites. Acta Physiol. Scand. suppl., 522, 9-18.

39. Bliss, T.V.P., Collingridge, G.L. 1993. A synaptic model of memory: long-term potentiation in the hippocampus. Nature, 361, 31-39.

40. Bliss, T.V.P., Lømo, T. 1973. Long-lasting potentiation of synaptic transmission in the dentate area of the anaesthetized rabbit following stimulation of the perforant path. J. Physiol., 232, 331-356.

41. Bohn, M.C., Cupit, L., Marciano, F., Gash, D.M. 1987. Adrenal grafts enhance recovery of striatal dopaminergic fibers. Science, 237, 913-916.

42. Bonilla, S., Hall, A.C., Pinto, L., Attardo, A., Gotz, M., Huttner, W.B., et al. 2008. Identification of midbrain floor plate radial glia-like cells as dopaminergic progenitors. Glia, 56, 809-20.

43. Bonner, J.F., Connors, T.M., Silverman, W.F., Kowalski, D.P., Lemay, M.A., Fischer, I. 2011. Grafted neural progenitors integrate and restore synaptic connectivity across the injured spinal cord. J. Neurosci., 31, 4675-4686. 
44. Brasted, P., Humby, T., Dunnett, S.B., Robbins, T.W. 1997. Unilateral lesions of the dorsal striatum in rats disrupt responding in egocentric space. J. Neurosci., 17, 8919-8926.

45. Brasted, P.J., Robbins, T.W., Dunnett, S.B. 1999a. Dissociable roles for striatal subregions in mediating response processing revealed by focal excitotoxic lesions. Behav. Neurosci., 113, 253-264.

46. Brasted, P.J., Robbins, T.W., Dunnett, S.B. 2000. Behavioral recovery after transplantation into a rat model of Huntington's disease requires both anatomical connectivity and extensive postoperative training. Behav. Neurosci., $114,431-436$.

47. Brasted, P.J., Watts, C., Robbins, T.W., Dunnett, S.B. 1999b. Associative plasticity in striatal transplants. Proc. Natl. Acad. Sci. U.S.A., 96, 10524-10529.

48. Brasted, P.J., Watts, C., Torres, E.M., Robbins, T.W., Dunnett, S.B. 1999c. Behavioural recovery following striatal transplantation: effects of postoperative training and P zone volume. Exp. Brain Res., 128, 535-538.

49. Braz, J.M., Sharif-Naeini, R., Vogt, D., Kriegstein, A., Alvarez-Buylla, A., Rubenstein, J.L., et al. 2012. Forebrain GABAergic neuron precursors integrate into adult spinal cord and reduce injury-induced neuropathic pain. Neuron, 74, 663-675.

50. Brecknell, J.E., Du, J.-S., Muir, E.M., Fidler, P.S., Hlavin, M.-L., Dunnett, S.B., et al. 1996a. Bridge grafts of fibroblast growth factor-4-secreting Schwannoma cells promote functional axonal regeneration in the nigrostriatal pathway of the adult rat. Neuroscience, 74, 775-784.

51. Brecknell, J.E., Haque, N.S., Du, J.S., Muir, E.M., Fidler, P.S., Hlavin, M.L., et al. 1996b. Functional and anatomical reconstruction of the 6-hydroxydopamine lesioned nigrostriatal system of the adult rat. Neuroscience, 71, 913-925.

52. Bregman, B.S. 1994. Recovery of function after spinal cord injury: transplantation strategies. In: Dunnett, S.B., Björklund, A. (eds.) Functional Neural Transplantation. New York: Raven Press, pp 489-529.

53. Bregman, B.S., Kunkel-Bagden, E., Reier, P.J., Dai, H.N., Mcatee, M., Gao, D. 1993. Recovery of function after spinal cord injury: mechanisms underlying transplantmediated recovery of function differ after spinal cord injury in newborn and adult rats. Exp. Neurol., 123, 3-16.

54. Brown, V.J., Robbins, T.W. 1989. Elementary processes of response selection mediated by distinct regions of the striatum. J. Neurosci., 9, 3760-3765.

55. Buchholz, D.E., Pennington, B.O., Croze, R.H., Hinman, C.R., Coffey, P.J., Clegg, D.O. 2013. Rapid and efficient directed differentiation of human pluripotent stem cells into retinal pigmented epithelium. Stem Cells Transl. Med., 2, 384-93.

56. Bunge, M.B., Wood, P.M. 2012. Realizing the maximum potential of Schwann cells to promote recovery from spinal cord injury. Handbook of Clinical Neurology, $109,523-540$.

57. Bunge, R.P., Kleitman, N., Ard, M.D., Duncan, I.D. 1988. Culture preparations of neuroglial cells useful for studies of myelin repair and axonal regeneration in the central nervous system. Prog. Brain Res., 78, 321-6.

58. Buzsaki, G., Gage, F.H. 1988. Mechanisms of action of neural grafts in the limbic system. Can. J. Neurol. Sci., 15, 99-105.

59. Cajal, S.R.Y. 1928. Degeneration and Regeneration of the Nervous System, Oxford, Oxford University Press.

60. Calabresi, P., Picconi, B., Tozzi, A., Di Filippo, M. 2007. Dopamine-mediated regulation of corticostriatal synaptic plasticity. Trends Neurosci., 30, 211-219. 
61. Calabresi, P., Pisani, A., Mercuri, N.B., Bernardi, G. 1992. Long-term potentiation in the striatum is unmasked by removing the voltage-dependent magnesium block of NMDA receptor channels. Eur. J. Neurosci., 4, 929-935.

62. Campbell, K., Kalén, P., Wictorin, K., Lundberg, C., Mandel, R.J., Björklund, A. 1993. Characterization of GABA release from intrastriatal striatal transplants: dependence on host-derived afferents. Neuroscience, 53, 403-415.

63. Carli, M., Evenden, J.L., Robbins, T.W. 1985. Depletion of unilateral striatal dopamine impairs initiation of contralateral actions and not sensory attention. Nature, 313, 679-682.

64. Carlstedt, T., Cullheim, S., Risling, M., Ulfhake, B. 1989. Nerve fibre regeneration across the PNS-CNS interface at the root-spinal cord junction. Brain Res. Bull., 22, 93-102.

65. Cassel, J.C., Kelche, C., Will, B. 1990. Time-dependent effects of intrahippocampal grafts in rats with fimbria-fornix lesions. Exp. Brain Res., 81, 179-190.

66. Chaturvedi, R.K., Agrawal, A.K., Seth, K., Shukla, S., Chauhan, S., Shukla, Y., et al. 2003. Effect of glial cell line-derived neurotrophic factor (GDNF) cotransplantation with fetal ventral mesencephalic cells (VMC) on functional restoration in 6-hydroxydopamine (6-OHDA) lesioned rat model of Parkinson's disease: neurobehavioral, neurochemical and immunohistochemical studies. Int. J. Dev. Neurosci., 21, 391-400.

67. Chen, G.J., Jeng, C.H., Lin, S.Z., Tsai, S.H., Wang, Y., Chiang, Y.H. 2002. Fetal striatal transplants restore electrophysiological sensitivity to dopamine in the lesioned striatum of rats with experimental Huntington's disease. J. Biomed. Sci., 9, 303310.

68. Chew, D.J., Fawcett, J.W., Andrews, M.R. 2012. The challenges of long-distance axon regeneration in the injured CNS. Prog. Brain Res., 201, 253-294.

69. Chudasama, Y., Dalley, J.W., Nathwani, F., Bouger, P., Robbins, T.W. 2004. Cholinergic modulation of visual attention and working memory: dissociable effects of basal forebrain 192-IgG-saporin lesions and intraprefrontal infusions of scopolamine. Learning \& Memory, 11, 78-86.

70. Clarke, D.J., Dunnett, S.B. 1993. Synaptic relationships between cortical and dopaminergic inputs and intrinsic GABAergic systems within intrastriatal striatal grafts. J. Chem. Neuroanat., 6, 147-158.

71. Clarke, D.J., Dunnett, S.B., Isacson, O., Sirinathsinghji, D.J.S., Björklund, A. 1988. Striatal grafts in rats with unilateral neostriatal lesions. I. Ultrastructural evidence of afferent synaptic inputs from the host nigrostriatal pathway. Neuroscience, 24, 791-801.

72. Clarke, D.J., Gage, F.H., Björklund, A. 1986. Formation of cholinergic synapses by intrahippocampal septal grafts revealed by choline acetyltransferase immunocytochemistry. Brain Res., 369, 151-162.

73. Clarke, D.J., Wictorin, K., Dunnett, S.B., Bolam, J.P. 1994. Internal composition of striatal grafts: light and electron microscopy. In: Percheron, G., Mckenzie, J.S., Féger, J. (eds.) The Basal Ganglia IV. New Ideas on Structure and Function. 41 ed. New York: Plenum Press, pp 189-196.

74. Collier, T.J., Springer, J.E. 1994. Neural graft augmentation through co-grafting: Implantation of cells as sources of survival and growth factors. Prog. Neurobiol., $44,309-331$. 
75. Cunningham, L.A., Hansen, J.T., Short, M.P., Bohn, M.C. 1991. The use of genetically altered astrocytes to provide nerve growth factor to adrenal chromaffin cells grafted into the striatum. Brain Res., 561, 192-202.

76. Czyz, M., Tabakow, P., Gheek, D., Mis, M., Jarmundowicz, W., Raisman, G. 2014. The supraorbital keyhole approach via an eyebrow incision applied to obtain the olfactory bulb as a source of olfactory ensheathing cells--radiological feasibility study. Br. J. Neurosurg., 28, 234-40.

77. Czyz, M., Tabakow, P., Hernandez-Sanchez, I., Jarmundowicz, W., Raisman, G. 2015. Obtaining the olfactory bulb as a source of olfactory ensheathing cells with the use of minimally invasive neuroendoscopy-assisted supraorbital keyhole approach--cadaveric feasibility study. Br. J. Neurosurg., 29, 362-70.

78. Daley, G.Q., Ahrlund-Richter, L., Auerbach, J.M., Benvenisty, N., Charo, R.A., Chen, G., et al. 2007. Ethics. The ISSCR guidelines for human embryonic stem cell research. Science, 315, 603-604.

79. Daley, G.Q., Hyun, I., Apperley, J.F., Barker, R.A., Benvenisty, N., Bredenoord, A.L., et al. 2016. Setting Global Standards for Stem Cell Research and Clinical Translation: The 2016 ISSCR Guidelines. Stem Cell Rep., 6, 1-11.

80. Dalrymple-Alford, J.C., Kelche, C., Cassel, J.C., Toniolo, G., Pallage, V., Will, B.E. 1988. Behavioral deficits after intrahippocampal fetal septal grafts in rats with selective fimbria-fornix lesions. Exp. Brain Res., 69, 545-558.

81. Das, G.D., Altman, J. 1971. Transplanted precursors of nerve cells: their fate in the cerebellums of young rats. Science, 173, 637-638.

82. Dascher-Nadel, C., Rosser, A.E., Dunnett, S.B. 2014. Repair-HD: human pluripotent stem cell differentiation, safety, and preparation for therapeutic transplantation in Huntington disease. HD Insights, 8, 9-10.

83. David, S., Aguayo, A.J. 1981. Axonal elongation into peripheral nervous system "bridges" after central nervous system injury in adult rats. Science, 214, 931-933.

84. Dawson, V.L., Gage, F.H., Hunt, M.A., Wamsley, J.K. 1989. Normalization of subtype-specific muscarinic receptor binding in the denervated hippocampus by septodiagonal band grafts. Exp. Neurol., 106, 115-124.

85. Deckel, A.W., Moran, T.H., Coyle, J.T., Sanberg, P.R., Robinson, R.G. 1986. Anatomical predictors of behavioral recovery following fetal striatal transplants. Brain Res., 365, 249-258.

86. Deckel, A.W., Robinson, R.G., Coyle, J.T., Sanberg, P.R. 1983. Reversal of long-term locomotor abnormalities in the kainic acid model of Huntington's disease by day 18 fetal striatal implants. Eur. J. Pharmacol., 92, 287-288.

87. Dekker, A.J., Winkler, J., Ray, J., Thal, L.J., Gage, F.H. 1994. Grafting of nerve growth factor-producing fibroblasts reduces behavioral deficits in rats with lesions of the nucleus basalis magnocellularis. Neuroscience, 60, 299-309.

88. Delli Carri, A., Onorati, M., Lelos, M.J., Castiglioni, V., Faedo, A., Menon, R., et al. 2013. Developmentally coordinated extrinsic signals drive human pluripotent stem cell differentiation towards fully functional DARPP-32 positive mediumsized spiny neurons. Development, 140, 301-312.

89. Deng, X., Liang, Y., Lu, H., Yang, Z., Liu, R., Wang, J., et al. 2013. Co-transplantation of GDNF-overexpressing neural stem cells and fetal dopaminergic neurons mitigates motor symptoms in a rat model of Parkinson's disease. PLoS One, 8, e80880.

90. Denham, M., Parish, C.L., Leaw, B., Wright, J., Reid, C.A., Petrou, S., et al. 2012. Neurons derived from human embryonic stem cells extend long-distance axonal 
projections through growth along host white matter tracts after intra-cerebral transplantation. Front. Cell. Neurosci., 6, 11.

91. Dickinson-Anson, H., Aubert, I., Gage, F.H., Fisher, L.J. 1998. Hippocampal grafts of acetylcholine-producing cells are sufficient to improve behavioural performance following a unilateral fimbria-fornix lesion. Neuroscience, 84, 771781.

92. Divac, I. 1972. Neostriatum and functions of prefrontal cortex. Acta Neurobiol. Exp., 32, 461-477.

93. Divac, I., Markowitsch, H.J., Pritzel, M. 1978. Behavioural and anatomical consequences of small intrastriatal injections of kainic acid in the rat. Brain Res., $151,523-532$.

94. Divac, I., Rosvold, H.E., Szwarcbart, M.K. 1967. Behavioral effects of selective ablation of the caudate nucleus. J. Comp. Physiol. Psychol., 63, 184-190.

95. Döbrössy, M.D., Dunnett, S.B. 1998. Striatal grafts alleviate deficits in response execution in a lateralised reaction time task. Brain Res. Bull., 47, 585-593.

96. Doeppner, T.R., Hermann, D.M. 2014. Stem cell-based treatments against stroke: observations from human proof-of-concept studies and considerations regarding clinical applicability. Front. Cell. Neurosci., 8, 357.

97. Doucet, G., Murata, Y., Brundin, P., Bosler, O., Mons, N., Geffard, M., et al. 1989. Host afferents into intrastriatal transplants of fetal ventral mesencephalon. Exp. Neurol., 106, 1-9.

98. Drucker-Colín, R., Aguilar-Roblero, R., García-Hernández, F., Fernández-Cancino, F., Bermúdez-Rattoni, F. 1984. Fetal suprachiasmatic nucleus transplants: diurnal rhythm recovery of lesioned rats. Brain Res., 311, 353-357.

99. Dulin, J.N., Lu, P. 2014. Bridging the injured spinal cord with neural stem cells. Neur. Regen. Res., 9, 229-31.

100. Dunnett, S.B. 1990. Neural transplantation in animal models of dementia. Eur. J. Neurosci., 2, 567-587.

101. Dunnett, S.B. 1991. Neural transplants as a treatment for Alzheimer's disease? Psychological Medicine, 21, 825-830.

102. Dunnett, S.B. 1995. Functional repair of striatal systems by neural transplants: evidence for circuit reconstruction. Behav. Brain Res., 66, 133-142.

103. Dunnett, S.B. 2006. Structural and functional repair of nerve circuits in the brain by neural transplants. SHAMS J. Med. Sci., 1, 22-46.

104. Dunnett, S.B. 2010. Chapter 55: neural transplantation. Handbook of Clinical Neurology, 95, 885-912.

105. Dunnett, S.B., Björklund, A. 1987. Mechanisms of function of neural grafts in the adult mammalian brain. J. Exp. Biol., 132, 265-289.

106. Dunnett, S.B., Björklund, A. (eds.) 1994a. Functional Neural Transplantation, New York: Raven Press.

107. Dunnett, S.B., Björklund, A. 1994b. Mechanisms of function of neural grafts in the injured brain. In: Dunnett, S.B., Björklund, A. (eds.) Functional Neural Transplantation. New York: Raven Press, pp 531-567.

108. Dunnett, S.B., Björklund, A. (eds.) 2000. Functional Neural Transplantation II: Novel Cell Therapies for CNS Disorders, Amsterdam, London \& New York: Elsevier.

109. Dunnett, S.B., Björklund, A. (eds.) 2012. Functional Neural Transplantation III. Vols I and II., Amsterdam: Elsevier. 
110. Dunnett, S.B., Isacson, O., Sirinathsinghji, D.J.S., Clarke, D.J., Björklund, A. 1988. Striatal grafts in rats with unilateral neostriatal lesions. III. Recovery from dopamine-dependent motor asymmetry and deficits in skilled paw reaching. Neuroscience, 24, 813-820.

111. Dunnett, S.B., Low, W.C., Iversen, S.D., Stenevi, U., Björklund, A. 1982. Septal transplants restore maze learning in rats with fornix-fimbria lesions. Brain Res., 251, 335-348.

112. Dunnett, S.B., Meldrum, A., Muir, J.L. 2005. Frontal-striatal disconnection disrupts cognitive performance of the frontal-type in the rat. Neuroscience, 135, 1055-1065.

113. Dunnett, S.B., Nathwani, F., Björklund, A. 2000. The integration and function of striatal grafts. Prog. Brain Res., 127, 345-380.

114. Dunnett, S.B., Nathwani, F., Brasted, P.J. 1999. Medial prefrontal and neostriatal lesions disrupt performance in an operant delayed alternation task in rats. Behav. Brain Res., 106, 13-28.

115. Dunnett, S.B., Rogers, D.C., Richards, S.J. 1989. Nigrostriatal reconstruction after 6-OHDA lesions in rats: combination of dopamine-rich nigral grafts and nigrostriatal bridge grafts. Exp. Brain Res., 75, 523-535.

116. Dunnett, S.B., Whishaw, I.Q., Rogers, D.C., Jones, G.H. 1987. Dopamine-rich grafts ameliorate whole body motor asymmetry and sensory neglect but not independent limb use in rats with 6- hydroxydopamine lesions. Brain Res., 415, 63-78.

117. Dunnett, S.B., White, A. 2006. Striatal grafts alleviate bilateral striatal lesion deficits in operant delayed alternation in the rat. Exp. Neurol., 199, 479489.

118. Einstein, O., Fainstein, N., Vaknin, I., Mizrachi-Kol, R., Reihartz, E., Grigoriadis, N., et al. 2007. Neural precursors attenuate autoimmune encephalomyelitis by peripheral immunosuppression. Ann. Neurol., 61, 209-218.

119. Ernfors, P., Ebendal, T., Olson, L., Mouton, P., Strömberg, I., Persson, H. 1989. A cell line producing recombinant nerve growth factor evokes growth responses in intrinsic and grafted central cholinergic neurons. Proc. Natl. Acad. Sci. U.S.A., 86, 4756-4760.

120. Espejo, E.F., Gonzalez-Albo, M.C., Moraes, J.P., El Banoua, F., Flores, J.A., Caraballo, I. 2001. Functional regeneration in a rat Parkinson's model after intrastriatal grafts of glial cell line-derived neurotrophic factor and transforming growth factor $\beta_{1}$-expressing extra-adrenal chromaffin cells of the Zuckerkandl's organ. J. Neurosci., 21, 9888-9895.

121. Espuny-Camacho, I., Michelsen, K.A., Gall, D., Linaro, D., Hasche, A., Bonnefont, J., et al. 2013. Pyramidal neurons derived from human pluripotent stem cells integrate efficiently into mouse brain circuits in vivo. Neuron, 77, 440456.

122. Evans, A.E., Kelly, C.M., Precious, S.V., Rosser, A.E. 2012. Molecular regulation of striatal development: a review. Anat. Res. Int., 2012, 106529.

123. Falci, S., Holtz, A., Åkesson, E., Azizi, M., Ertzgaard, P., Hultling, C., et al. 1997. Obliteration of a posttraumatic spinal cord cyst with solid human embryonic spinal cord grafts: First clinical attempt. J. Neurotrauma, 14, 875-884. 124. Fawcett, J.W., Rosser, A.E., Dunnett, S.B. 2001. Brain Damage, Brain Repair, Oxford and New York, Oxford University Press. 
125. Fisher, L.J., Young, S.J., Tepper, J.M., Groves, P.M., Gage, F.H. 1991. Electrophysiological characteristics of cells within mesencephalon suspension grafts. Neuroscience, 40, 109-122.

126. Forssman, J. 1898. Ueber die Ursachen, welche die Wachsthumsrichtung der peripheren Nervenfasern bei der Regeneration bestimmen. Unpublished thesis, University of Lund. Jena: Verlag.

127. Foster, G.A., Schultzberg, M., Gage, F.H., Björklund, A., Hökfelt, T., Nornes, H., et al. 1985. Transmitter expression and morphological development of embryonic medullary and mesencephalic raphe neurons after transplantation to the adult rat central nervous system. 1. Grafts to the spinal cord. Exp. Brain Res., $60,427-444$.

128. Freed, C.R., Greene, P.E., Breeze, R.E., Tsai, W.Y., Dumouchel, W., Kao, R., et al. 2001. Transplantation of embryonic dopamine neurons for severe Parkinson's disease. N. Engl. J. Med., 344, 710-719.

129. Freed, W.J., De Medinaceli, L., Wyatt, R.J. 1985. Promoting functional plasticity in the damaged nervous system. Science, 227, 1544-1552.

130. Freed, W.J., Poltorak, M., Becker, J.B. 1990. Intracerebral adrenal medulla grafts: a review. Exp. Neurol., 110, 139-166.

131. Freeman, T.B., Cicchetti, F., Bachoud-Lévi, A.C., Dunnett, S.B. 2011.

Technical factors that influence neural transplant safety in Huntington's disease. Exp. Neurol., 227, 1-9.

132. Fricker-Gates, R.A., Shin, J.J., Tai, C.C., Catapano, L.A., Macklis, J.D. 2002. Late-stage immature neocortical neurons reconstruct interhemispheric connections and form synaptic contacts with increased efficiency in adult mouse cortex undergoing targeted neurodegeneration. J. Neurosci., 22, 4045-4056.

133. Frim, D.M., Uhler, T.A., Galpern, W.R., Beal, M.F., Breakefield, X.O., Isacson, 0. 1994. Implanted fibroblasts genetically engineered to produce brain derived neurotrophic factor prevent 1-methyl-4-phenylpyridinium toxicity to dopaminergic neurons in the rat. Proc. Natl. Acad. Sci. U.S.A., 91, 5104-5108.

134. Gaffan, D. 1996. Memory, action and the corpus striatum - current developments in the memory-habit distinction. Semin. Neurosci., 8, 33-38.

135. Gage, F.H., Björklund, A., Stenevi, U., Dunnett, S.B., Kelly, P.a.T. 1984. Intrahippocampal septal grafts ameliorate learning impairments in aged rats. Science, 225, 533-536.

136. Gage, F.H., Buzsaki, G. 1989. CNS grafting: potential mechanisms of action. In: Seil, F.J. (ed.) Neural Regeneration and Transplantation. New York: Alan Liss, pp 211-226.

137. Gage, F.H., Stenevi, U., Carlstedt, T., Foster, G., Björklund, A., Aguayo, A.J. 1985. Anatomical and functional consequences of grafting mesencephalic neurons into a peripheral nerve bridge connected to the denervated striatum. Exp. Brain Res., 60, 584-589.

138. Gaillard, A., Decressac, M., Frappe, I., Fernagut, P.O., Prestoz, L., Besnard, S., et al. 2009. Anatomical and functional reconstruction of the nigrostriatal pathway by intranigral transplants. Neurobiol. Dis., 35, 477-488.

139. Gaillard, A., Prestoz, L., Dumartin, B., Cantereau, A., Morel, F., Roger, M., et al. 2007. Reestablishment of damaged adult motor pathways by grafted embryonic cortical neurons. Nat. Neurosci., 10, 1294-1299.

140. Gaillard, A., Roger, M. 2000. Early commitment of embryonic neocortical cells to develop area-specific thalamic connections. Cereb. Cort., 10, 443-453. 
141. Gaillard, F., Domballe, L., Gaillard, A. 2004. Fetal cortical allografts project massively through the adult cortex. Neuroscience, 126, 631-637.

142. Garcia, K.O., Ornellas, F.L., Martin, P.K., Patti, C.L., Mello, L.E., Frussa-Filho, R., et al. 2014. Therapeutic effects of the transplantation of VEGF overexpressing bone marrow mesenchymal stem cells in the hippocampus of murine model of Alzheimer's disease. Front. Aging Neurosci., 6, 30.

143. Gash, D.M. 1987. Neural transplantation: potential therapy for Alzheimer's disease. J. Neural Transm. suppl., 24, 301-308.

144. Gash, D.M., Sladek, J.R. (eds.) 1988. Transplantation into the Mammalian CNS., Amsterdam: Elsevier.

145. Gash, D.M., Sladek, J.R., Sladek, C.D. 1980. Functional development of grafted vasopressin neurons. Science, 210, 1367-1369.

146. Gaspard, N., Bouschet, T., Hourez, R., Dimidschstein, J., Naeije, G., Van Den, A.J., et al. 2008. An intrinsic mechanism of corticogenesis from embryonic stem cells. Nature, 455, 351-357.

147. Gibbs, R.B., Anderson, K.J., Cotman, C.W. 1986. Factors affecting innervation in the CNS: comparison of three cholinergic cell types transplanted to the hippocampus of adult rats. Brain Res., 383, 362-366.

148. Graybiel, A.M., Liu, F.C., Dunnett, S.B. 1989. Intrastriatal grafts derived from fetal striatal primordia. 1. Phenotypy and modular organization. J. Neurosci., 9, 3250-3271.

149. Grealish, S., Diguet, E., Kirkeby, A., Mattsson, B., Heuer, A., Bramoulle, Y., et al. 2014. Human ESC-derived dopamine neurons show similar preclinical efficacy and potency to fetal neurons when grafted in a rat model of Parkinson's disease. Cell Stem Cell, 15, 653-65.

150. Gubellini, P., Pisani, A., Centonze, D., Bernardi, G., Calabresi, P. 2004. Metabotropic glutamate receptors and striatal synaptic plasticity: implications for neurological diseases. Prog. Neurobiol., 74, 271-300.

151. Hallett, M., Litvan, I., Dis, T.F.S.P. 1999. Evaluation of surgery for Parkinson's disease - A report of the therapeutics and technology assessment subcommittee of the American Academy of Neurology. Neurology, 53, 19101921.

152. Hargraves, R., Freed, W.J. 1987. Chronic intrastriatal dopamine infusions in rats with unilateral lesions of the substantia nigra. Life. Sci., 40, 959-66.

153. Hauser, R.A., Furtado, S., Cimino, C.R., Delgado, H., Eichler, S., Schwartz, S., et al. 2002. Bilateral human fetal striatal transplantation in Huntington's disease. Neurology, 58, 687-695.

154. Helm, G.A., Palmer, P.E., Bennett, J.P. 1990. Fetal neostriatal transplants in the rat: a light and electron microscopic Golgi study. Neuroscience, 37, 735-756.

$155 . \quad H e n d e r s o n$, K.W., Gupta, J., Tagliatela, S., Litvina, E., Zheng, X., Van Zandt, M.A., et al. 2014. Long-term seizure suppression and optogenetic analyses of synaptic connectivity in epileptic mice with hippocampal grafts of GABAergic interneurons. J. Neurosci., 34, 13492-504.

156. Hernit-Grant, C.S., Macklis, J.D. 1996. Embryonic neurons transplanted to regions of targeted photolytic cell death in adult mouse somatosensory cortex re-form specific callosal projections. Exp. Neurol., 139, 131-142.

157. Hunt, R.F., Girskis, K.M., Rubenstein, J.L., Alvarez-Buylla, A., Baraban, S.C. 2013. GABA progenitors grafted into the adult epileptic brain control seizures and abnormal behavior. Nat. Neurosci., 16, 692-697. 
158. Ibrahim, A., Li, D., Collins, A., Tabakow, P., Raisman, G., Li, Y. 2014. Comparison of olfactory bulbar and mucosal cultures in a rat rhizotomy model. Cell Transplant., 23, 1465-70.

159. Isacson, O., Brundin, P., Kelly, P.a.T., Gage, F.H., Björklund, A. 1984. Functional neuronal replacement by grafted striatal neurons in the ibotenic acid lesioned rat striatum. Nature, 311, 458-460.

160. Isacson, O., Deacon, T.W. 1996. Specific axon guidance factors persist in the adult brain as demonstrated by pig neuroblasts transplanted to the rat. Neuroscience, 75, 827-837.

161. Isacson, O., Dunnett, S.B., Björklund, A. 1986. Graft-induced behavioral recovery in an animal model of Huntington disease. Proc. Natl. Acad. Sci. U.S.A., $83,2728-2732$.

162. Joyce, J.N., Gibbs, R.B., Cotman, C.W., Marshall, J.F. 1989. Regulation of muscarinic receptors in hippocampus following cholinergic denervation and reinnervation by septal and striatal transplants. J. Neurosci., 9, 2776-2791.

163. Kadoya, K., Lu, P., Nguyen, K., Lee-Kubli, C., Kumamaru, H., Yao, L., et al. 2016. Spinal cord reconstitution with homologous neural grafts enables robust corticospinal regeneration. Nat. Med., 22, 479-87.

164. Kawaja, M.D., Rosenberg, M.B., Yoshida, K., Gage, F.H. 1992. Somatic gene transfer of nerve growth factor promotes the survival of axotomized septal neurons and the regeneration of their axons in adult rats. J. Neurosci., 12, 28492864.

165. Keyvan-Fouladi, N., Li, Y., Raisman, G. 2002. How do transplanted olfactory ensheathing cells restore function? Brain Res. Rev., 40, 325-327.

166. Keyvan-Fouladi, N., Raisman, G., Li, Y. 2003. Functional repair of the corticospinal tract by delayed transplantation of olfactory ensheathing cells in adult rats. J. Neurosci., 23, 9428-9434.

167. Kiatpongsan, S., Sipp, D. 2009. Medicine. Monitoring and regulating offshore stem cell clinics. Science, 323, 1564-1565.

168. Kirkeby, A., Grealish, S., Wolf, D.A., Nelander, J., Wood, J., Lundblad, M., et al. 2012. Generation of regionally specified neural progenitors and functional neurons from human embryonic stem cells under defined conditions. Cell Reports, 1, 703-714.

169. Koide, K., Hashitani, T., Aihara, N., Mabe, H., Nishino, H. 1993. Improvement of passive avoidance task after grafting of fetal striatal cell suspensions in ischemic striatum in the rat. Rest. Neurol. Neurosci., 5, 205-214.

170. Krieger, D.T., Perlow, M.J., Gibson, M.J., Davies, T.F., Zimmerman, E.A., Ferin, M., et al. 1982. Brain grafts reverse hypogonadism of gonadotropin releasing hormone deficiency. Nature, 298, 468-471.

171. Kriks, S., Shim, J.W., Piao, J., Ganat, Y.M., Wakeman, D.R., Xie, Z., et al. 2011. Dopamine neurons derived from human ES cells efficiently engraft in animal models of Parkinson's disease. Nature, 480, 547-551.

172. Kromer, L.F., Björklund, A., Stenevi, U. 1981. Regeneration of the septohippocampal pathway in adult rats is promoted by utilizing embryonic hippocampal implants as bridges. Brain Res., 210, 173-200.

173. Labandeira-García, J.L., Guerra, M.J. 1994. Cortical stimulation induces fos expression in intrastriatal striatal grafts. Brain Res., 652, 87-97. 
174. Labandeira-García, J.L., Wictorin, K., Cunningham, E.T., Björklund, A. 1991. Development of intrastriatal striatal grafts and their afferent innervation from the host. Neuroscience, 42, 407-426.

175. Lai, R.C., Chen, T.S., Lim, S.K. 2011. Mesenchymal stem cell exosome: a novel stem cell-based therapy for cardiovascular disease. Regen. Med., 6, 481-92.

176. Leanza, G., Martìnez-Serrano, A., Björklund, A. 1998. Amelioration of spatial navigation and short-term memory deficits by grafts of foetal basal forebrain tissue placed into the hippocampus and cortex of rats with selective cholinergic lesions. Eur. J. Neurosci., 10, 2353-2370.

177. Leanza, G., Nikkhah, G., Nilsson, O.G., Wiley, R.G., Björklund, A. 1996. Extensive reinnervation of the hippocampus by embryonic basal forebrain cholinergic neurons grafted into the septum of neonatal rats with selective cholinergic lesions. J. Comp. Neurol., 373, 355-372.

178. Lewis, E.R., Cotman, C.W. 1983. Neurotransmitter characteristics of brain grafts: striatal and septal tissues form the same laminated input to the hippocampus. Neuroscience, 8, 57-66.

179. Li, Y., Decherchi, P., Raisman, G. 2003. Transplantation of olfactory ensheathing cells into spinal cord lesions restores breathing and climbing. J. Neurosci., 23, 727-731.

180. Li, Y., Field, P.M., Raisman, G. 1997. Repair of adult rat corticospinal tract by transplants of olfactory ensheathing cells. Science, 277, 2000-2002.

181. Li, Y., Field, P.M., Raisman, G. 1998. Regeneration of adult rat corticospinal axons induced by transplanted olfactory ensheathing cells. J. Neurosci., 18, 10514-10524.

182. Li, Y., Li, D., Raisman, G. 2016. Functional repair of rat corticospinal tract lesions does not require permanent survival of an immunoincompatible transplant. Cell Transplant., 25, 293-9.

183. Li, Y., Raisman, G. 1993. Long axon growth from embryonic neurons transplanted into myelinated tracts of the adult rat spinal cord. Brain Res., 629, 115-127.

184. Li, Y.J., Simon, J.R., Low, W.C. 1992. Intrahippocampal grafts of cholinergicrich striatal tissue ameliorate spatial memory deficits in rats with fornix lesions. Brain Res. Bull., 29, 147-155.

185. Liang, Y., Agren, L., Lyczek, A., Walczak, P., Bulte, J.W. 2013. Neural progenitor cell survival in mouse brain can be improved by co-transplantation of helper cells expressing bFGF under doxycycline control. Exp. Neurol., 247, 73-79.

186. Lindvall, O., Brundin, P., Widner, H., Rehncrona, S., Gustavii, B., Frackowiak, R., et al. 1990. Grafts of fetal dopamine neurons survive and improve motor function in Parkinson's disease. Science, 247, 574-577.

187. Liu, F.C., Graybiel, A.M., Dunnett, S.B., Baughman, R.W. 1990. Intrastriatal grafts derived from fetal striatal primordia. 2. Reconstitution of cholinergic and dopaminergic systems. J. Comp. Neurol., 295, 1-14.

188. Low, W.C., Lewis, P.R., Bunch, S.T., Dunnett, S.B., Thomas, S.R., Iversen, S.D., et al. 1982. Function recovery following neural transplantation of embryonic septal nuclei in adult rats with septohippocampal lesions. Nature, $300,260-262$.

189. Lu, P., Blesch, A., Tuszynski, M.H. 2001. Neurotrophism without neurotropism: BDNF promotes survival but not growth of lesioned corticospinal neurons. J. Comp. Neurol., 436, 456-70. 
190. Lu, P., Wang, Y., Graham, L., Mchale, K., Gao, M., Wu, D., et al. 2012. Longdistance growth and connectivity of neural stem cells after severe spinal cord injury. Cell, 150, 1264-73.

191. Lu, P., Woodruff, G., Wang, Y., Graham, L., Hunt, M., Wu, D., et al. 2014. Long-distance axonal growth from human induced pluripotent stem cells after spinal cord injury. Neuron, 83, 789-96.

192. Lund, R.D., Hauschka, S.D. 1976. Transplanted neural tissue develops connections with host rat brain. Science, 193, 582-585.

193. Mack, G.S. 2011. ReNeuron and StemCells get green light for neural stem cell trials. Nat. Biotechnol., 29, 95-97.

194. Mandel, R.J., Wictorin, K., Cenci, M.A., Björklund, A. 1992. Fos expression in intrastriatal striatal grafts: regulation by host dopaminergic afferents. Brain Res., 583, 207-215.

195. Marei, H.E., Farag, A., Althani, A., Afifi, N., A, A.E., Lashen, S., et al. 2015. Human olfactory bulb neural stem cells expressing hNGF restore cognitive deficit in Alzheimer's disease rat model. Journal of Cellular Physiology, 230, 116-30.

196. Martinez-Cerdeno, V., Noctor, S.C., Espinosa, A., Ariza, J., Parker, P., Orasji, S., et al. 2010. Embryonic MGE precursor cells grafted into adult rat striatum integrate and ameliorate motor symptoms in 6-OHDA-lesioned rats. Cell Stem Cell, 6, 238-250.

197. Martinez-Serrano, A., Fischer, W., Björklund, A. 1995a. Reversal of agedependent cognitive impairments and cholinergic neuron atrophy by NGFsecreting neural progenitors grafted to the basal forebrain. Neuron, 15, 473-484.

198. Martinez-Serrano, A., Lundberg, C., Horellou, P., Fischer, W., Bentlage, C., Campbell, K., et al. 1995b. CNS-derived neural progenitor cells for gene transfer of nerve growth factor to the adult rat brain: Complete rescue of axotomized cholinergic neurons after transplantation into the septum. J. Neurosci., 15, 56685680.

199. Martino, G. 2016. Bench-to-bedside translation of stem cell therapies: where are we now and where are we going? Regen. Med., 11, 347-349.

200. Martino, G., Pluchino, S. 2006. The therapeutic potential of neural stem cells. Nat. Rev. Neurosci., 7, 395-406.

201. Mayer, E., Brown, V.J., Dunnett, S.B., Robbins, T.W. 1992. Striatal graftassociated recovery of a lesion-induced performance deficit in the rat requires learning to use the transplant. Eur. J. Neurosci., 4, 119-126.

202. Mazzocchi-Jones, D., Döbrössy, M.D., Dunnett, S.B. 2009. Synaptic plasticity in striatal grafts. Eur. J. Neurosci., 30, 2134-2142.

203. Mazzocchi-Jones, D., Döbrössy, M.D., Dunnett, S.B. 2011. Environmental enrichment facilitates long-term potentiation in embryonic striatal grafts. Neurorehabil. Neural Rep., 25, 548-557.

204. Michelsen, K.A., Acosta-Verdugo, S., Benoit-Marand, M., Espuny-Camacho, I., Gaspard, N., Saha, B., et al. 2015. Area-specific reestablishment of damaged circuits in the adult cerebral cortex by cortical neurons derived from mouse embryonic stem cells. Neuron, 85, 982-97.

205. Montoya, C.P., Astell, S., Dunnett, S.B. 1990. Effects of nigral and striatal grafts on skilled forelimb use in the rat. Prog. Brain Res., 82, 459-466.

206. Nakao, N., Ogura, M., Nakai, K., Itakura, T. 1999. Embryonic striatal grafts restore neuronal activity of the globus pallidus in a rodent model of Huntington's disease. Neuroscience, 88, 469-477. 
207. Nakao, N., Yokote, H., Nakai, K., Itakura, T. 2000. Promotion of survival and regeneration of nigral dopamine neurons in a rat model of Parkinson's disease after implantation of embryonal carcinoma-derived neurons genetically engineered to produce glial cell line-derived neurotrophic factor. J. Neurosurg., 92, 659-670.

208. Niijima, K., Chalmers, G.R., Peterson, D.A., Fisher, L.J., Patterson, P.H., Gage, F.H. 1995. Enhanced survival and neuronal differentiation of adrenal chromaffin cells cografted into the striatum with NGF-producing fibroblasts. J. Neurosci., 15, 1180-1194.

209. Nilsson, O.G., Brundin, P., Björklund, A. 1990a. Amelioration of spatial memory impairment by intrahippocampal grafts of mixed septal and raphe tissue in rats with combined cholinergic and serotonergic denervation of the forebrain. Brain Res., 515, 193-206.

210. Nilsson, O.G., Brundin, P., Widner, H., Strecker, R.E., Björklund, A. 1988a. Human fetal basal forebrain neurons grafted to the denervated rat hippocampus produce an organotypic cholinergic reinnervation pattern. Brain Res., 456, 193198.

211. Nilsson, O.G., Clarke, D.J., Brundin, P., Björklund, A. 1988b. Comparison of growth and reinnervation properties of cholinergic neurons from different brain regions grafted to the hippocampus. J. Comp. Neurol., 268, 204-222.

212. Nilsson, O.G., Kalén, P., Rosengren, E., Björklund, A. 1990b. Acetylcholine release from intrahippocampal septal grafts is under control by the host brain: a microdialysis study. Prog. Brain Res., 82, 321-328.

213. Nilsson, O.G., Kalén, P., Rosengren, E., Björklund, A. 1990c. Acetylcholine release from intrahippocampal septal grafts is under control of the host brain. Proc. Natl. Acad. Sci. U.S.A., 87, 2647-2651.

214. Nilsson, O.G., Shapiro, M.L., Gage, F.H., Olton, D.S., Björklund, A. 1987. Spatial learning and memory following fimbria-fornix transection and grafting of fetal septal neurons to the hippocampus. Exp. Brain Res., 67, 195-215.

215. Nilsson, O.G., Strecker, R.E., Daszuta, A., Björklund, A. 1988c. Combined cholinergic and serotonergic denervation of the forebrain produces severe deficits in a spatial learning task in the rat. Brain Res., 453, 235-246.

216. Nishino, H., Koide, K., Aihara, N., Mitzukawa, K., Nagai, H. 1992. Striatal grafts in infarct striatum after occlusion of the middle cerebral artery improve passive avoidance/water maze learning, GABA release and GABAa receptor deficits in the rat. Rest. Neurol. Neurosci., 4, 178-178.

217. Nornes, H., Björklund, A., Stenevi, U. 1983. Reinnervation of the denervated adult spinal cord of rats by intraspinal transplants of embryonic brain stem neurons. Cell and Tissue Research, 230, 15-35.

218. Olanow, C.W., Goetz, C.G., Kordower, J.H., Stoessl, A.J., Sossi, V., Brin, M.F., et al. 2003. A double-blind controlled trial of bilateral fetal nigral transplantation in Parkinson's disease. Ann. Neurol., 54, 403-414.

219. Olson, L., Ayer-Lelievre, C., Ebendal, T., Eriksdotter-Nilsson, M., Ernfors, P., Henschen, A., et al. 1990. Grafts, growth factors and grafts that make growth factors. Prog. Brain Res., 82, 55-66.

220. Ono, Y., Nakatani, T., Sakamoto, Y., Mizuhara, E., Minaki, Y., Kumai, M., et al. 2007. Differences in neurogenic potential in floor plate cells along an anteroposterior location: midbrain dopaminergic neurons originate from mesencephalic floor plate cells. Development, 134, 3213-25. 
221. Packard, M.G., Knowlton, B.J. 2002. Learning and memory functions of the basal ganglia. Ann. Rev. Neurosci., 25, 563-593.

222. Paganini, M., Biggeri, A., Romoli, A.M., Mechi, C., Ghelli, E., Berti, V., et al. 2014. Fetal striatal grafting slows motor and cognitive decline of Huntington's disease. J. Neurol. Neurosurg. Psychiat., 85, 974-81.

223. Perlmutter, J.S., Mink, J.W. 2006. Deep brain stimulation. Ann. Rev. Neurosci., 29, 229-257.

224. Perlow, M.J., Freed, W.J., Hoffer, B.J., Seiger, Å., Olson, L., Wyatt, R.J. 1979. Brain grafts reduce motor abnormalities produced by destruction of nigrostriatal dopamine system. Science, 204, 643-647.

225. Perry, T., Hodges, H., Gray, J.A. 2001. Behavioural, histological and immunocytochemical consequences following 192 IgG-saporin immunolesions of the basal forebrain cholinergic system. Brain Res. Bull., 54, 29-48.

226. Pfisterer, U., Kirkeby, A., Torper, O., Wood, J., Nelander, J., Dufour, A., et al. 2011. Direct conversion of human fibroblasts to dopaminergic neurons. Proc. Natl. Acad. Sci. U.S.A., 108, 10343-10348.

227. Piccini, P., Pavese, N., Hagell, P., Reimer, J., Björklund, A., Oertel, W.H., et al. 2005. Factors affecting the clinical outcome after neural transplantation in Parkinson's disease. Brain, 128, 2977-2986.

228. Precious, S.V., Rosser, A.E. 2012. Producing striatal phenotypes for transplantation in Huntington's disease. Exp. Biol. Med., 237, 343-351.

229. Pritzel, M., Isacson, O., Brundin, P., Wiklund, L., Björklund, A. 1986. Afferent and efferent connections of striatal grafts implanted into the ibotenic acid lesioned neostriatum in adult rats. Exp. Brain Res., 65, 112-126.

230. Raisman, G. 2001. Olfactory ensheathing cells - another miracle cure for spinal cord injury? Nat. Rev. Neurosci., 2, 369-375.

231. Ralph, M.R., Foster, R.G., Davis, F.C., Menaker, M. 1990. Transplanted suprachiasmatic nucleus determines circadian period. Science, 247, 975-978.

232. Ramsden, C.M., Da Cruz, L., Coffey, P.J. 2016. Stemming the tide of agerelated macular degeneration: New therapies for old retinas. Investigative ophthalmology \& visual science, 57, ORSFb1-3.

233. Reuter, I., Tai, Y.F., Pavese, N., Chaudhuri, K.R., Mason, S., Polkey, C.E., et al. 2008. Long-term clinical and positron emission tomography outcome of fetal striatal transplantation in Huntington's disease. J. Neurol. Neurosurg. Psychiat., 79, 948-951.

234. Richardson, P.M., Mcguinness, U.M., Aguayo, A.J. 1980. Axons from CNS neurons regenerate into PNS grafts. Nature, 284, 264-5.

235. Richardson, P.M., Mcguinness, U.M., Aguayo, A.J. 1982. Peripheral nerve autografts to the rat spinal cord: studies with axonal tracing methods. Brain Res., $237,147-62$.

236. Richter-Levin, G., Segal, M. 1989. Raphe cells grafted into the hippocampus can ameliorate spatial memory deficits in rats with combined serotonergic cholinergic deficiencies. Brain Res., 478, 184-186.

237. Ridley, R.M., Baker, H.F. 1994. Cognitive function after intracerebral grafting in monkeys. In: Dunnett, S.B., Björklund, A. (eds.) Functional Neural Transplantation. New York: Raven Press, pp 327-346.

238. Rosser, A.E., Kelly, C.M., Dunnett, S.B. 2011. Cell transplantation for Huntington's disease: practical and clinical considerations. Future Neurology, 6, 45-62. 
239. Rosvold, H.E. 1972. The frontal lobe system: cortical-subcortical interrelationships. Acta Neurobiol. Exp., 32, 439-460.

240. Rosvold, H.E., Szwarcbart, M.K. 1964. Neural structures involved in delayed response performance. In: Warren, J.M., Akert, K. (eds.) The Frontal Granular Cortex and Behavior. New York: McGraw-Hill, pp 1-15.

241. Rutherford, A., Garcia-Muñoz, M., Dunnett, S.B., Arbuthnott, G.W. 1987. Electrophysiological demonstration of host cortical inputs to striatal grafts. Neurosci. Lett., 83, 275-281.

242. Schwab, M.E., Caroni, P. 1988. Oligodendrocytes and CNS myelin are nonpermissive substrates for neurite growth and fibroblast spreading in vitro. $J$. Neurosci., 8, 2381-93.

243. Segal, M., Björklund, A., Gage, F.H. 1985. Transplanted septal neurons make viable cholinergic synapses with a host hippocampus. Brain Res., 336, 302307.

244. Semba, K. 2000. Multiple output pathways of the basal forebrain: organization, chemical heterogeneity, and roles in vigilance. Behav. Brain Res., 115, 117-41.

245. Senut, M.C., Tuszynski, M.H., Raymon, H.K., Suhr, S.T., Liou, N.H., Jones, K.R., et al. 1995. Regional differences in responsiveness of adult CNS axons to grafts of cells expressing human neurotrophin 3. Exp. Neurol., 135, 36-55.

246. Shin, E., Palmer, M.J., Li, M., Fricker, R.A. 2012. GABAergic neurons from mouse embryonic stem cells possess functional properties of striatal neurons in vitro, and develop into striatal neurons in vivo in a mouse model of Huntington's disease. Stem Cell Rev., 8, 513-531.

247. Sinden, J.D., Gray, J.A., Hodges, H. 1994. Cholinergic grafts and cognitive function. In: Dunnett, S.B., Björklund, A. (eds.) Functional Neural Transplantation. New York: Raven Press, pp 253-293.

248. Sirinathsinghji, D.J.S., Dunnett, S.B., Isacson, O., Clarke, D.J., Kendrick, K., Björklund, A. 1988. Striatal grafts in rats with unilateral neostriatal lesions. II. In vivo monitoring of GABA release in globus pallidus and substantia nigra. Neuroscience, 24, 803-811.

249. Sirinathsinghji, D.J.S., Heavens, R.P., Torres, E.M., Dunnett, S.B. 1993. Cholecystokinin-dependent regulation of host dopamine inputs to striatal grafts. Neuroscience, 53, 651-663.

250. Sorensen, A.T., Thompson, L., Kirik, D., Björklund, A., Lindvall, O., Kokaia, M. 2005. Functional properties and synaptic integration of genetically labelled dopaminergic neurons in intrastriatal grafts. Eur. J. Neurosci., 21, 2793-2799.

251. Sotelo, C., Alvarado-Mallart, R.M. 1987. Reconstruction of the defective cerebellar circuitry in adult Purkinje cell degeneration mutant mice by Purkinje cell replacement through transplantation of solid embryonic implants. Neuroscience, 20, 1-22.

252. Sotelo, C., Alvarado-Mallart, R.M. 1991. The reconstruction of cerebellar circuits. Trends Neurosci., 14, 350-355.

253. Southwell, D.G., Nicholas, C.R., Basbaum, A.I., Stryker, M.P., Kriegstein, A.R., Rubenstein, J.L., et al. 2014. Interneurons from embryonic development to cellbased therapy. Science, 344, 1240622.

254. Steinbeck, J.A., Choi, S.J., Mrejeru, A., Ganat, Y., Deisseroth, K., Sulzer, D., et al. 2015. Optogenetics enables functional analysis of human embryonic stem cell- 
derived grafts in a Parkinson's disease model. Nat Biotechnol. United States, pp 204-9.

255. Steinbeck, J.A., Koch, P., Derouiche, A., Brustle, O. 2012. Human embryonic stem cell-derived neurons establish region-specific, long-range projections in the adult brain. Cellular and Molecular Life Sciences, 69, 461-470.

256. Stenevi, U., Björklund, A., Svendgaard, N.-A. 1976. Transplantation of central and peripheral monoamine neurons to the adult rat brain: techniques and conditions for survival. Brain Res., 114, 1-20.

257. Strömberg, I., Wetmore, C.J., Ebendal, T., Ernfors, P., Persson, H., Olson, L. 1990. Rescue of basal forebrain cholinergic neurons after implantation of genetically modified cells producing recombinant NGF. J. Neurosci. Res., 25, 405411.

258. Sundberg, M., Bogetofte, H., Lawson, T., Jansson, J., Smith, G., Astradsson, A., et al. 2013. Improved cell therapy protocols for Parkinson's disease based on differentiation efficiency and safety of hESC-, hiPSC-, and non-human primate iPSC-derived dopaminergic neurons. Stem Cells, 31, 1548-62.

259. Tabakow, P., Jarmundowicz, W., Czapiga, B., Fortuna, W., Miedzybrodzki, R., Czyz, M., et al. 2013. Transplantation of autologous olfactory ensheathing cells in complete human spinal cord injury. Cell Transplant., 22, 1591-1612.

260. Tajiri, N., Kaneko, Y., Shinozuka, K., Ishikawa, H., Yankee, E., Mcgrogan, M., et al. 2013. Stem cell recruitment of newly formed host cells via a successful seduction? Filling the gap between neurogenic niche and injured brain site. PLoS One, 8, e74857.

261. Takayama, H., Ray, J., Raymon, H.K., Baird, A., Hogg, J., Fisher, L.J., et al. 1995. Basic fibroblast growth factor increases dopaminergic graft survival and function in a rat model of Parkinson's disease. Nat. Med., 1, 53-58.

262. Tanaka, D.H., Toriumi, K., Kubo, K., Nabeshima, T., Nakajima, K. 2011. GABAergic precursor transplantation into the prefrontal cortex prevents phencyclidine-induced cognitive deficits. J. Neurosci., 31, 14116-14125.

263. Tarricone, B.J., Keim, S.R., Simon, J.R., Low, W.C. 1991. Intrahippocampal transplants of septal cholinergic neurons: high-affinity choline uptake and spatial memory function. Brain Res., 548, 55-62.

264. Tello, F. 1911. La influencia del neurotropismo en la regeneracion de las contros nerviosos. Trabajos del Laboratorio de Investigaciones Biologicas de la Universidad de Madrid, 9, 123-159.

265. Thompson, L.H., Grealish, S., Kirik, D., Björklund, A. 2009. Reconstruction of the nigro-striatal dopamine pathway in the adult mouse brain. Eur. J. Neurosci., $30,625-638$.

266. Torres, E.M., Perry, T.A., Blokland, A., Wilkinson, L.S., Wiley, R.G., Lappi, D.A., et al. 1994. Behavioural, histochemical and biochemical consequences of selective immunolesions in discrete regions of the basal forebrain cholinergic system. Neuroscience, 63, 95-112.

267. Uccelli, A., Mancardi, G. 2010. Stem cell transplantation in multiple sclerosis. Curr. Opin. Neurol., 23, 218-225.

268. Uteza, Y., Rouillot, J.S., Kobetz, A., Marchant, D., Pecqueur, S., Arnaud, E., et al. 1999. Intravitreous transplantation of encapsulated fibroblasts secreting the human fibroblast growth factor 2 delays photoreceptor cell degeneration in Royal College of Surgeons rats. Proc. Natl. Acad. Sci. U.S.A., 96, 3126-3131. 
269. Wallace, R.B., Das, G.D. (eds.) 1983. Neural Tissue Transplantation Research, New York, Berlin, Heidelberg and Tokyo: Springer-Verlag.

270. Walsh, J.P., Zhou, F.C., Hull, C.D., Fisher, R.S., Levine, M.S., Buchwald, N.A. 1988. Physiological and morphological characterization of striatal neurons transplanted into the striatum of adult rats. Synapse, 2, 37-44.

271. Wang, L.J., Zhang, R.P., Li, J.D. 2014. Transplantation of neurotrophin-3expressing bone mesenchymal stem cells improves recovery in a rat model of spinal cord injury. Acta Neurochir., 156, 1409-18.

272. Wendt, J.S., Fagg, G.E., Cotman, C.W. 1983. Regeneration of rat hippocampal fimbria fibers after fimbria transection and peripheral nerve or fetal hippocampal implantation. Exp. Neurol., 79, 452-61.

273. White, A., Dunnett, S.B. 2006. Fronto-striatal disconnection disrupts operant delayed alternation performance in the rat. NeuroReport, 17, 435-441.

274. White, N.M. 1989. Reward or reinforcement. What's the difference? Neurosci. Biobehav. Rev., 13, 181-186.

275. White, T.E., Lane, M.A., Sandhu, M.S., O'steen, B.E., Fuller, D.D., Reier, P.J. 2010. Neuronal progenitor transplantation and respiratory outcomes following upper cervical spinal cord injury in adult rats. Exp. Neurol., 225, 231-236.

276. Wichterle, H., García-Verdugo, J.M., Herrera, D.G., Alvarez-Buylla, A. 1999. Young neurons from medial ganglionic eminence disperse in adult and embryonic brain. Nat. Neurosci., 2, 461-466.

277. Wictorin, K. 1992. Anatomy and connectivity of intrastriatal striatal transplants. Prog. Neurobiol., 38, 611-639.

278. Wictorin, K., Björklund, A. 1989. Connectivity of striatal grafts implanted into the ibotenic acid- lesioned striatum. 2. Cortical afferents. Neuroscience, 30, 297-311.

279. Wictorin, K., Brundin, P., Gustavii, B., Lindvall, O., Björklund, A. 1990a. Reformation of long axon pathways in adult rat central nervous system by human forebrain neuroblasts. Nature, 347, 556-558.

280. Wictorin, K., Clarke, D.J., Bolam, J.P., Björklund, A. 1989a. Host corticostriatal fibres establish synaptic connections with grafted striatal neurons in the ibotenic acid lesioned striatum. Eur. J. Neurosci., 1, 189-195.

281. Wictorin, K., Clarke, D.J., Bolam, J.P., Björklund, A. 1990b. Fetal striatal neurons grafted into the ibotenate lesioned adult striatum: efferent projections and synaptic contacts in the host globus pallidus. Neuroscience, 37, 301-315.

282. Wictorin, K., Isacson, O., Fischer, W., Nothias, F., Peschanski, M., Björklund, A. 1988. Connectivity of striatal grafts implanted into the ibotenic acid-lesioned striatum. 1. Subcortical afferents. Neuroscience, 27, 547-562.

283. Wictorin, K., Lagenaur, C.F., Lund, R.D., Björklund, A. 1991. Efferent projections to the host brain from intrastriatal striatal mouse-to-rat grafts: time course and tissue-type specificity as revealed by a mouse specific neuronal marker. Eur. J. Neurosci., 3, 86-101.

284. Wictorin, K., Ouimet, C.C., Björklund, A. 1989b. Intrinsic organization and connectivity of intrastriatal striatal transplants in rats as revealed by DARPP-32 immunohistochemistry: specificity of connections with the lesioned host brain. Eur. J. Neurosci., 1, 690-701.

$285 . \quad$ Wictorin, K., Simerly, R.B., Isacson, O., Swanson, L.W., Björklund, A. 1989c. Connectivity of striatal grafts implanted into the ibotenic acid- lesioned striatum. 
3. Efferent projecting graft neurons and their relation to host afferents within the grafts. Neuroscience, 30, 313-330.

286. Wijeyekoon, R., Barker, R.A. 2009. Cell replacement therapy for Parkinson's disease. Biochim. Biophys. Acta, 1792, 688-702.

287. Wilby, M., Sinclair, S.R., Muir, E.M., Zietlow, R., Adcock, K.H., Horellou, P., et al. 1999. A GDNF-secreting clone of the Schwann cell line SCTM41 enhances survival and fibre outgrowth from embryonic nigral neurones grafted to the striatum and the lesioned substantia nigra. J. Neurosci., 19, 2301-2312.

$288 . \quad$ Winkler, J., Suhr, S.T., Gage, F.H., Thal, L.J., Fisher, L.J. 1995. Essential role of neocortical acetylcholine in spatial memory. Nature, 375, 484-487.

289. Worthington, D.R., Harvey, A.R. 1990. Organization of visual cortical projections to fetal tectal transplants in rats: a study using multiple retrograde tracers. Brain Res., 536, 153-162.

290. Xu, Z.C., Wilson, C.J., Emson, P.C. 1991. Synaptic potentials evoked in spiny neurons in rat neostriatal grafts by cortical and thalamic stimulation. Journal of Neurophysiology, 65, 477-493.

291. Yoshimoto, Y., Lin, Q., Collier, T.J., Frim, D.M., Breakefield, X.O., Bohn, M.C. 1995. Astrocytes retrovirally transduced with BDNF elicit behavioral improvement in a rat model of Parkinson's disease. Brain Res., 691, 25-36. 